\title{
Synoptic and Large-Scale Determinants of Extreme Austral Frost Events
}

\author{
James S. Risbey, Didier P. Monselesan, Terence J. O'Kane, Carly R. Tozer, \\ AND MichAEL J. POOK \\ CSIRO Oceans and Atmosphere, Hobart, Tasmania, Australia \\ PETER T. HAYMAN \\ South Australian Research and Development Institute, Urrbrae, South Australia, Australia
}

(Manuscript received 21 May 2018, in final form 6 March 2019)

\begin{abstract}
We define and examine extreme frost events at three station locations across southern Australia. A synoptic assessment of the events shows that they are generally characterized by passage of a front or trough followed by a developing blocking high. Frost typically occurs at the leading edge of the block. The very cold air pool leading to the frost event is the result of descent of cold, dry midtropospheric air parcels from regions poleward of the station. The air is exceptionally cold because it is advected across the strong meridional temperature gradients in the storm track. The air is dry because this equatorward meridional pathway requires descent and so must have origins well above the surface in the dryer midtroposphere. The position of the block and location of the dry descent are dynamically determined by large-scale waveguide modes in the polar jet waveguide. The role of the waveguide modes is deduced from composites of midtropospheric flow anomalies over the days preceding and after the frost events. These show organized wavenumber 3 or 4 wave trains, with the block associated with the frost formed as a node of the wave train. The wave trains resemble known waveguide modes such as the Pacific-South America mode, and the frost event projects clearly onto these modes during their life cycle. The strong interannual and decadal variability of extreme frost events at a location can be understood in light of event dependence on organized waveguide modes.
\end{abstract}

\section{Introduction}

Severe frosts cause damages to a range of different crops around the world. In the Southern Hemisphere, frosts are a particular problem for the grains industry, where the typical winter crop calendar for wheat entails planting in autumn and harvesting in late spring. That timing means that the plant is at its most vulnerable growing stages in late winter and spring when frosts can still occur. Frost damage reduces grain yields (sometimes dramatically) and grain quality. The Grains Research and Development Corporation in Australia estimates that frost damages cost the industry about $\$ 360$ million AUD per year.

Given the importance of frost, there has been much research to examine its causes, particularly at local and synoptic scales. This includes work at local scales to examine surface energy processes, radiation loss,

Corresponding author: James S. Risbey, james.risbey@csiro.au ground moisture, ground cover, and local circulation (Avissar and Mahrer 1988), and at synoptic scales related to frontal passages, troughs, and high pressure systems (Schultz et al. 1998; Simmonds and Richter 2000; Müller et al. 2003). There is also research on the large-scale circulation and frost (Schultz et al. 1998; Müller et al. 2005; Xie et al. 2019). In the Southern Hemisphere, there is a developed literature on South American frost events. In particular, frosty months in southern South America (months with a high frequency of frost events covering a broad region) have been explained in terms of their synoptic basis (Müller and Berri 2007, 2012), and further by the organization of the synoptics by large-scale waveguide modes (Müller and Ambrizzi 2007; Müller et al. 2008).

This work is also directed at synoptic and large-scale causes of frost. We examine frost events in three representative sites in the Australian grains belt to assess why it occurs, and whether it has common synoptic associations. We also address the issue of why the synoptic 
elements of frosts (frontal passage followed by high pressure system) are relatively common through a season at any given location, but extreme frosts at a given location are relatively rare (some years may even pass without frost in a given location). The answer to this question requires an analysis of the types of synoptic systems giving rise to extreme frosts (typically blocking highs), the circulation associated with these systems, and the factors that give rise to blocks in the Australian region. The variability of blocking highs in the region is controlled by largerscale modes of variability in the Southern Hemisphere circulation (Ambrizzi et al. 1995; O'Kane et al. 2016, 2017), and thus we include assessment of large-scale modes and frost.

The large-scale modes in the extratropics are typically expressed as annular modes (Lorenz 1951; Thompson and Wallace 1998), dipole modes (Wallace and Gutzler 1981), or waveguide modes (Branstator 2002). In the Southern Hemisphere the more zonal circulation yields mainly annular (Thompson and Solomon 2002) and waveguide (O'Kane et al. 2016) modes. The large-scale modes of variability examined here in relationship to frost are primarily waveguide modes (Branstator 2002), meaning that they form in the waveguide channels associated with the hemispheric jet streams (Hoskins and Ambrizzi 1993; Ambrizzi et al. 1995). The waveguide modes have been associated with a range of climate extremes including drought (Teng and Branstator 2017), heat waves (Teng et al. 2013; Risbey et al. 2018), cold events (Krishnamurti et al. 1999; Simmonds and Rashid 2001; Pezza and Ambrizzi 2005; Müller and Ambrizzi 2007; Ashcroft et al. 2009; Harnik et al. 2016), and extreme rainfall (Feldstein and Dayan 2008; Tozer et al. 2018).

The waveguide modes are conducive to extremes because they allow for persistent or recurring flow, and because the nodes in the modes create strong meridional flow excursions (Risbey et al. 2018). In the Southern Hemisphere in particular, zonal flow predominates in the extratropics (Ambrizzi et al. 1995), which is not conducive to extremes of temperature because it circulates air masses at similar latitudes, and therefore similar temperatures (Risbey et al. 2018). Temperature extremes such as frost rely on those occasions when the flow is strongly meridional to transport cold, dry air from high latitudes (Garfinkel and Harnik 2017). We assess these flow excursions here by back-trajectory analysis of air parcels leading up to frost events. For completeness, we include the southern annular mode (SAM) in analysis here, though because of its more zonal structure, it is less associated with localized meridional excursions of the flow.
In the work that follows, we provide a description of the frost events, an assessment of their synoptics and air parcel histories, and then relate those synoptic configurations to the large-scale waveguide modes. This provides a framework to describe the factors controlling the variability of extreme frosts in the Australian region and their basis for prediction and projection.

\section{Definitions, data, and diagnostics}

\section{a. Frost events}

Frost has a synoptic association and so whole regions can be frosted, with degrees of severity within the region set by local topography and mesoscale processes. In some work relating frost to synoptic and large-scale processes, the signature of frost is averaged in space and/ or time. For example, Müller and Ambrizzi (2007) assess the frequency of frost days in a season for an area (the Pampas in Argentina) where a specified percentage of the weather stations observe minimum temperatures below $0^{\circ} \mathrm{C}$. Harnik et al. (2016) average temperature across the eastern United States and choose cold events as the largest negative anomalies of 5-day running mean temperature anomaly. The advantage of choosing a temporally averaged or summed index of frost or cold is that it builds in a degree of persistence and thus tends to select for more persistent circulation modes. The more persistent circulation modes tend to occur on large spatial scales, and so temporal averaging helps relate frost events to the larger-scale modes.

In this work we defined both frost events (single day events) and cold spells (persistent periods of belowaverage minimum temperature) to assess the role of temporal averaging on the association with large-scale circulation modes. In both cases we used station data and so did not area average. Cold spells were defined as three or more consecutive days where the minimum temperature at a station was below the 10th percentile. This definition was used to mirror that used for heat waves [based on three consecutive days of maximum temperature above the 90th percentile (Risbey et al. 2018)], where clear associations with waveguide modes have been found. Frost events were defined as days where the minimum temperature at the station was below the 1.5 percentile (where the percentile statistics are based on a moving 15-day window centered about each calendar day), and where the minimum temperature must be below a frost threshold value for the station, typically set at $0^{\circ}$ or $2^{\circ} \mathrm{C}$ depending on the station. Both conditions must be satisfied, so that frost events are 


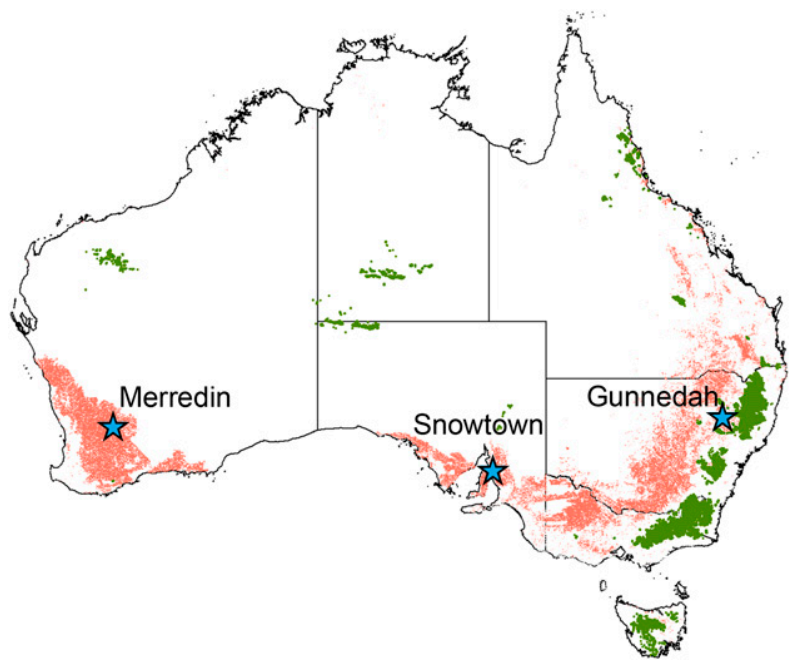

FIG. 1. Locations of the stations used for frost event analysis. The red stippled areas show the major dryland cropping regions in Australia. The green-shaded areas mark topography over $1000 \mathrm{~m}$.

some of the coldest days experienced, and would likely result in frost and cold damage in grain crops. By allowing either a $0^{\circ}$ or $2^{\circ} \mathrm{C}$ threshold at a station, we ensure that the number of samples (extreme cold days) is not too different for our different station composites, facilitating comparisons across regions. The addition of the percentile criterion is not part of standard meteorological definitions of frost, but it helps provide a more consistent and comparable sample of events in the cold tail of the minimum temperature distribution.

Frost typically occurs at temperatures below the freezing point. For grain crops the vulnerable part of the plant is near the ground, but official temperatures are often measured a meter or so above the ground in an enclosure, where it can be appreciably warmer than the surface and grain head during a frost. Thus, frosts can occur at ground level when recorded temperatures at the $2-\mathrm{m}$ level may be $2^{\circ} \mathrm{C}$ or more (Frederiks et al. 2015).

The comparison of composites of the large-scale circulation for frost events and cold spells showed that the (persistent) cold spells do yield clearer patterns for the large-scale modes, though they are broadly similar. Since one of our motivations is to understand the circulations giving rise to frost damage in grains, we stick to frost events (rather than cold spells) for this paper. In contrast to heat waves, where the impact on humans can depend on cumulative conditions, frost damage in the Australian grains belt is typically due to damage to the plant reproductive organs from single day events (Barlow et al. 2015; Zheng et al. 2015; Flohr et al. 2017).

\section{b. Data}

The station data selected for this analysis are the Australian Climate Observations Reference NetworkSurface Air Temperature (ACORN-SAT) station data (Trewin 2013). This is a dedicated high-quality dataset

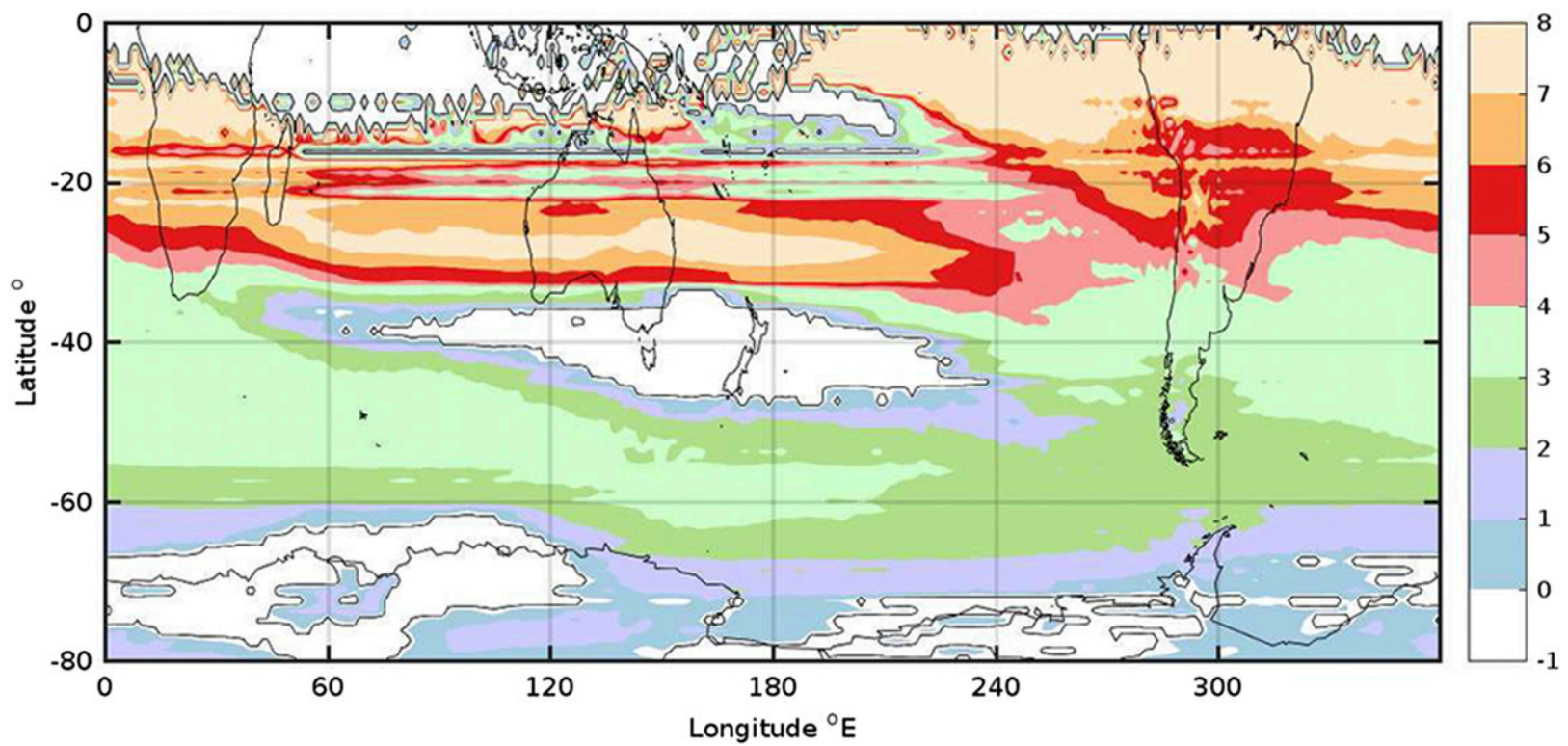

FIG. 2. Climatological mean distribution of $K_{s}$ for winter. Wavenumbers greater than 8 are shown in the same color as wavenumbers 7-8. Values of $K_{s}^{2}<0$ are represented by the white color. 


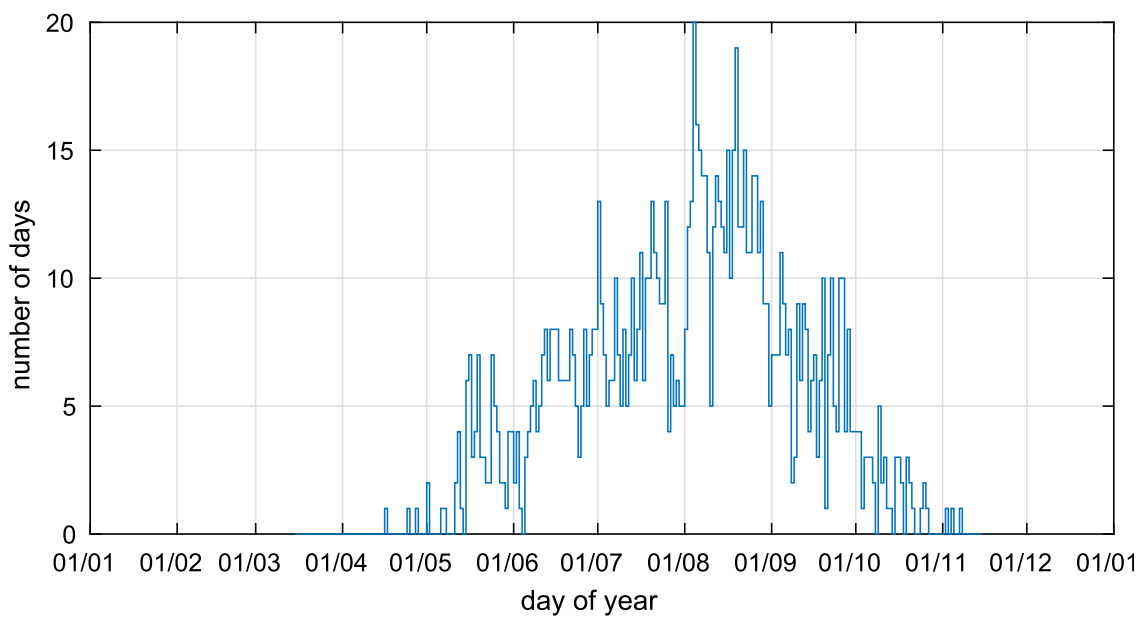

FIG. 3. Number of days that are less than $0^{\circ} \mathrm{C}$ as a function of day of year for Snowtown. This histogram of frost frequency is based on minimum temperatures from all days in the Snowtown station record.

that is appropriate for the study of extreme temperatures. To assess frost events, we select representative station sites in the southwest (Merredin), south (Snowtown), and northeast (Gunnedah) part of the Australian grains belt. The locations of these sites are shown in Fig. 1. These locations have different characteristic winter synoptic conditions characterized by prevalence of a longwave trough and frontal passages in Merredin, influence of longwave ridge and cutoff lows in Snowtown, and easterly troughs in Gunnedah (Pook et al. 2013; Risbey et al. 2013).

For each frost event, we seek to characterize the atmospheric flow at synoptic and large-scale for days prior to the frost, on the frost, and following the frost. For this purpose we use the JRA-55 reanalysis (Kobayashi et al. 2015), which provides a high-resolution

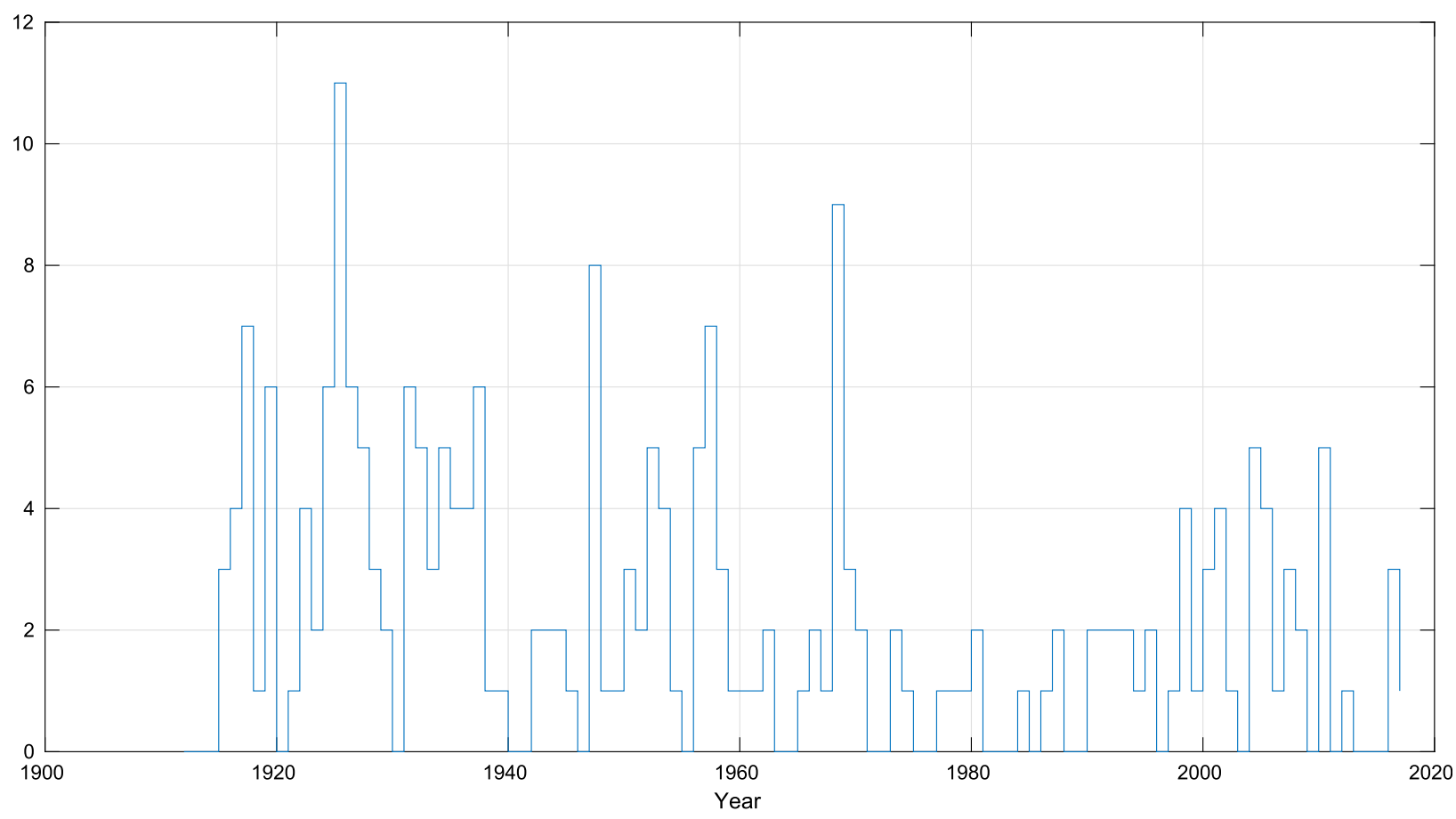

FIG. 4. Annual number of days that are less than $0^{\circ} \mathrm{C}$ during spring at Merredin, based on minimum temperatures for all spring days in the Merredin record. 


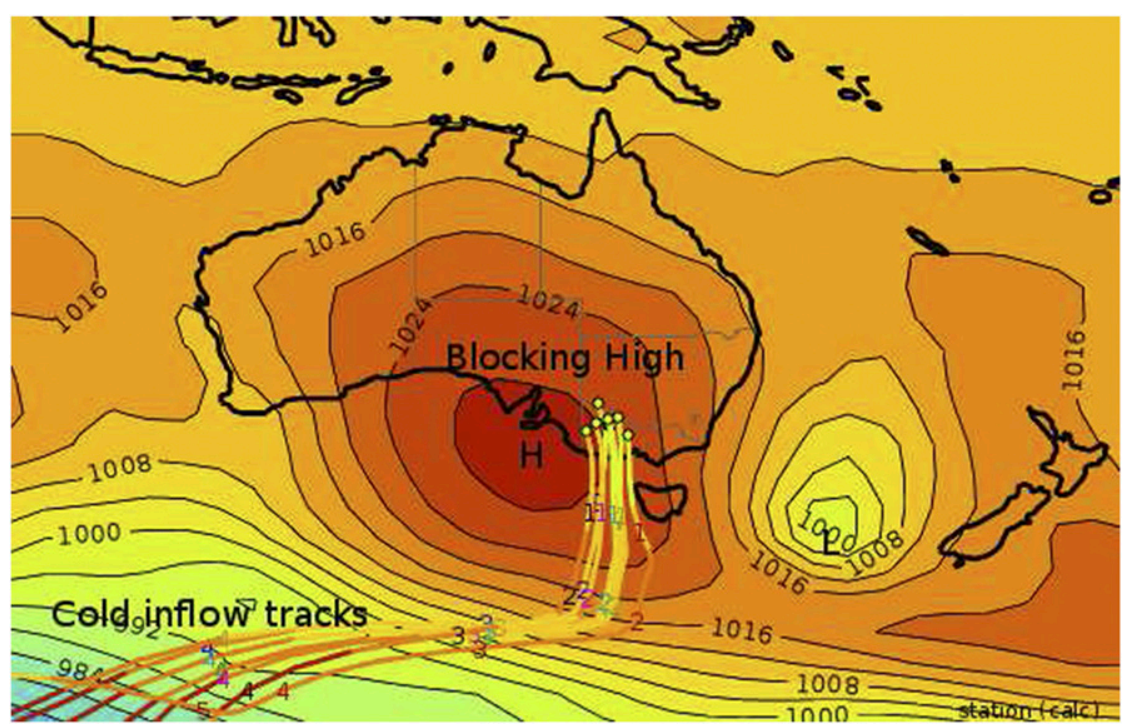

FIG. 5. Back parcel trajectories from $925 \mathrm{hPa}$ at 0000 UTC 23 Oct 2016. The parcels are tracked back from a range of locations close to Snowtown until they exit the plotted domain, typically after 5 days. The contoured field is mean sea level pressure. The numbers on the tracks indicate the number of days prior to the final track time. The yellow and brown colors on the tracks indicate very low specific humidity.

(1.25 latitude by longitude), four-dimensional variational analysis from 1958 to the present. We composite the reanalysis flow for a suite of variables for composites typically 10 days prior to 10 days post the frost events.
The day of the frost event is designated as day 0 . The composite analysis is performed separately for winter (June, July, and August) and spring (September, October, and November) frost events. In the results that
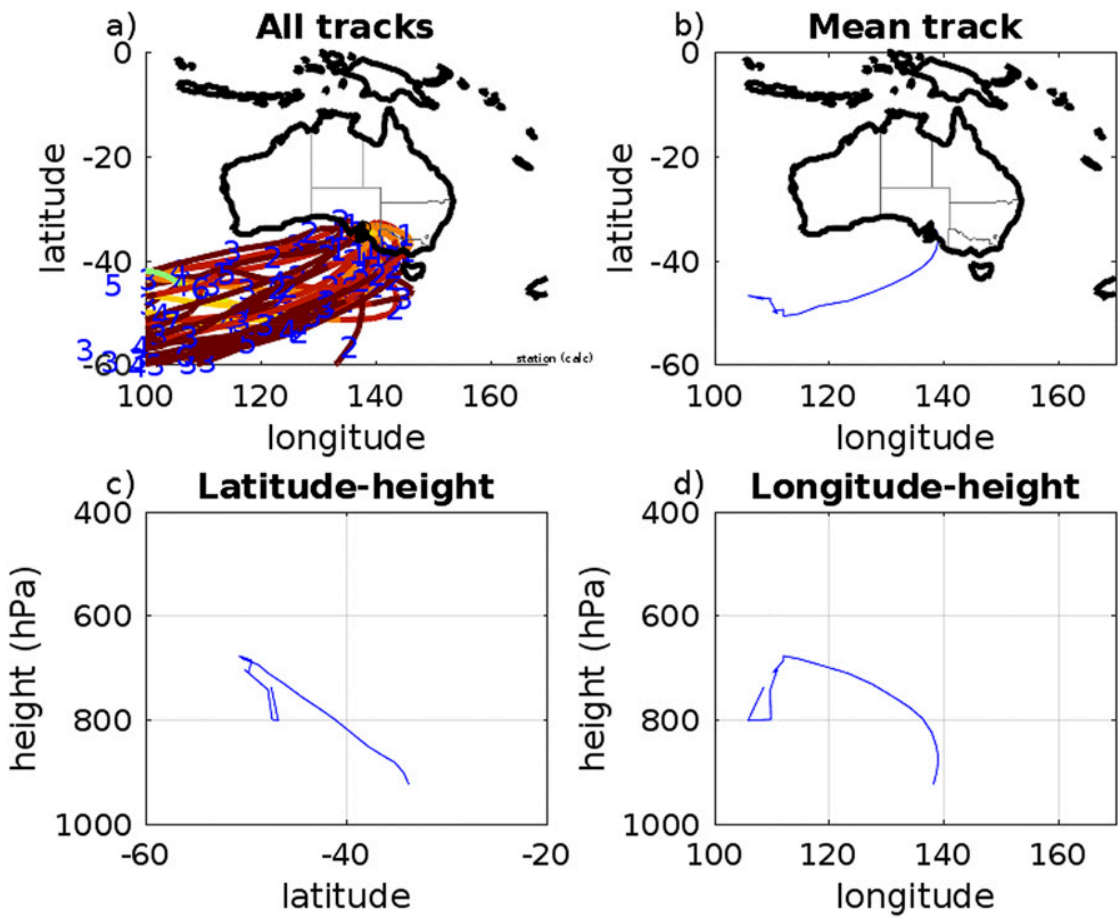

FIG. 6. Back parcel trajectories for extreme frost events at Snowtown: (a) all event trajectories, where the numbers on the tracks indicate the number of days prior to the final track time, (b) the mean frost event trajectory, and vertical cross sections of the mean trajectory as a function of (c) latitude and (d) longitude. 


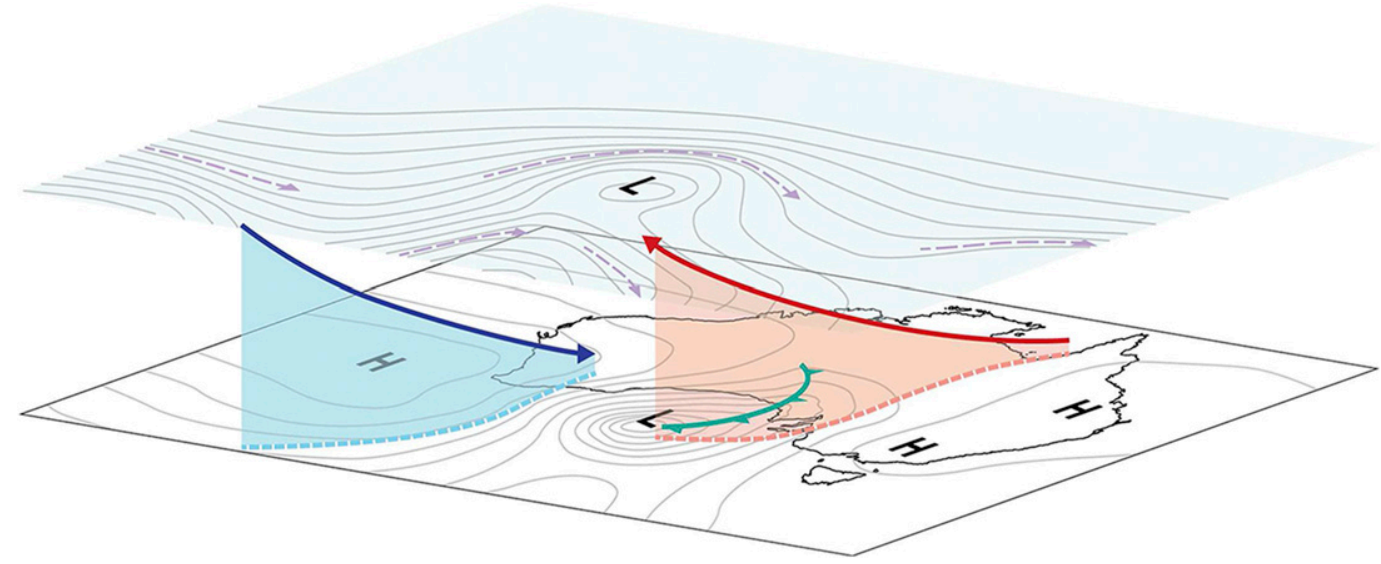

FIG. 7. Schematic representation of back parcel trajectories for frost events in Merredin. The red arrow depicts the warm upslope flow (warm conveyor belt) ahead of the front. The blue arrow depicts the cold downslope flow at the leading edge of the approaching high pressure system. The surface contours are mean sea level pressure and indicate the passage of a cutoff low followed by the approaching high from the west. The midtropospheric contours are 500-hPa geopotential height and indicate the ridge and trough configuration above the surface high and low, with purple arrows indicating the direction of horizontal flow.

follow, we show winter results for Merredin and Snowtown and spring results for Gunnedah, with broadly similar composite results in both seasons.

For each frost event we also performed a backtrajectory analysis in which an air parcel was back tracked from $925 \mathrm{hPa}$ at the location of the station using the three-dimensional wind field to determine the parcel's location at times prior to the frost event (McIntosh et al. 2007). For this analysis, we used six-hourly wind fields from the NCEP/NCAR reanalysis (Kalnay et al. 1996). The back trajectories are made from $925 \mathrm{hPa}$ rather than the surface. This level is close enough to the surface to give a good indication of where the surface air parcel originated, and it provides a consistent indication of the free-tropospheric synoptic flow. Back trajectories from the surface are less indicative of the synoptic flow because they are influenced by a range of surface mesoscale processes.

\section{c. Diagnostics}

To diagnose the atmospheric flow associated with frost events we use mean sea level pressure to depict the surface flow and 500-hPa geopotential height $Z_{500}$ to represent the midtropospheric flow. To better depict the signature of wavelike structures in the midtropospheric flow we show anomalies of geopotential height $Z_{500}^{\prime}$ for the frost event composites. The anomalies are calculated as departures from the daily climatological mean value. The climatology is calculated over 1958-2017.

The waveguide modes form in the channels created by the major jet streams where Rossby waves can propagate and are preferentially refracted. A good diagnostic to indicate when and where such channels are formed is the stationary Rossby wavenumber $K_{s}$. The stationary Rossby wavenumber is the total wavenumber at which a barotropic Rossby wave is stationary (Hoskins and Ambrizzi 1993). The wavenumber is defined for an idealized background (time mean) zonal flow $\bar{U}$ as

$$
K_{s}=a \cos \phi(\beta / \bar{U})^{1 / 2},
$$

where $\beta$ is the meridional absolute vorticity gradient, $a$ is the radius of Earth, and $\phi$ is latitude (Newman and Sardeshmukh 1998). Here we set $\bar{U}$ to the climatological mean $U$ wind for each calendar day. Stationary Rossby waves are refracted toward larger values of $K_{s}$ and do not propagate where $K_{s}^{2}<0$. These properties of $K_{s}$ allow it to highlight the regions where stationary waves are confined to channels in the jet streams (Hoskins and Ambrizzi 1993; Ambrizzi et al. 1995). Local maxima of $K_{s}$ form in the channels that are bounded by regions where $K_{s}^{2}<0$.

These characteristics are evident in Fig. 2, which shows the winter climatological mean distribution of $K_{s}$ at $200 \mathrm{hPa}$. Winter in the Southern Hemisphere is characterized by the split subtropical and polar jets, with a corresponding split in the jet waveguide regions. The subtropical waveguide region is marked by wavenumbers $4-8$ near $25^{\circ} \mathrm{S}$, and the polar waveguide is marked by wavenumbers $2-4$ near $50^{\circ} \mathrm{S}$. Between these regions there is a broad area around $40^{\circ} \mathrm{S}$ where $K_{s}^{2}<0$ (white shading in Fig. 2) that presents a barrier to stationary Rossby waves emanating from the tropics (Ambrizzi et al. 1995; O'Kane et al. 2017). 


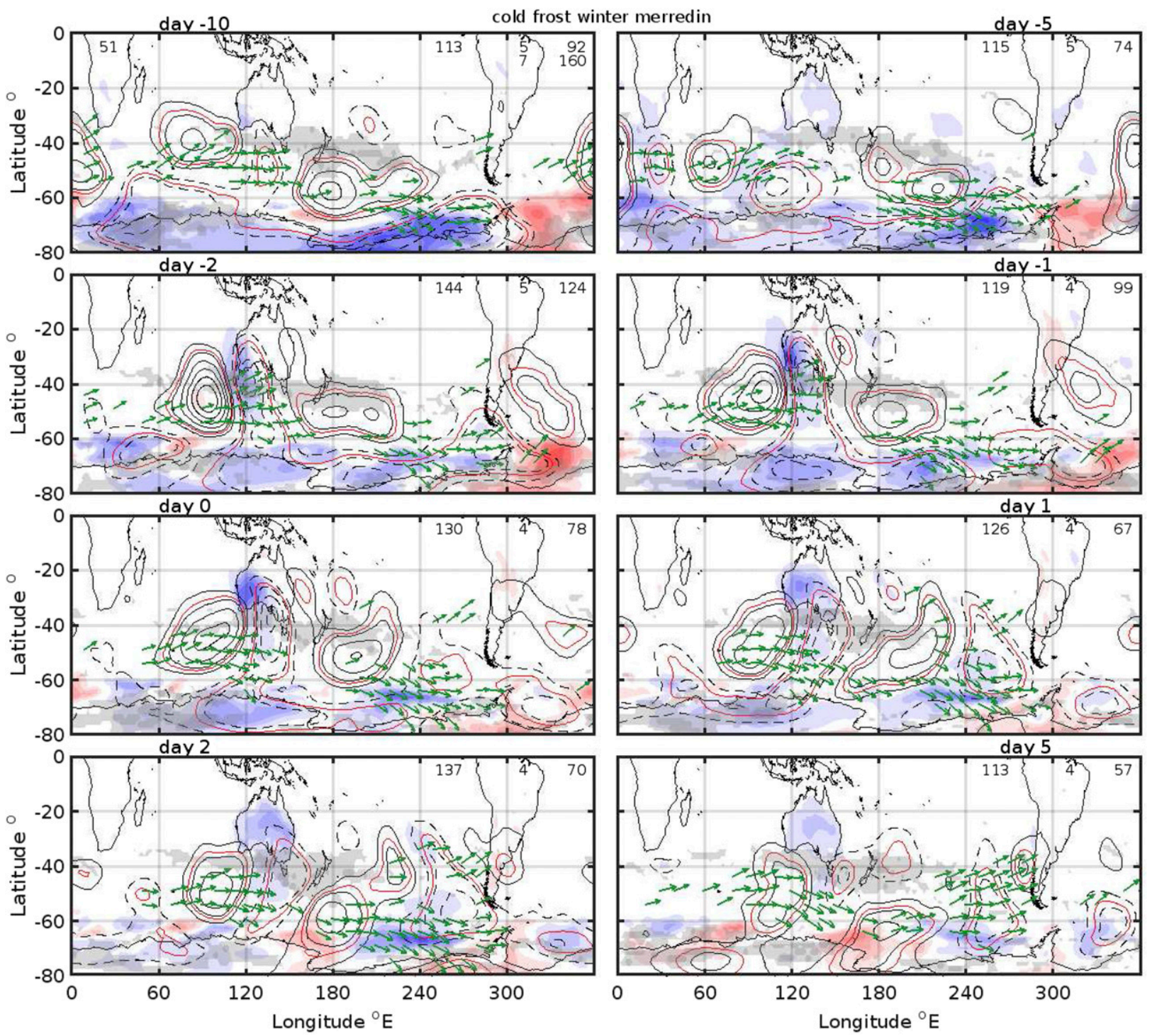

FIG. 8. Composite circulation for frost events at Merredin for days $-10,-5,-2,-1,0,+1,+2$, and +5 about events. The black contour lines show $Z_{500}$ anomalies (m), the red and blue shading show $T_{\text {surf }}$ anomalies $(\mathrm{K})$, and the green vectors are wave activity flux $\mathbf{W}_{s}\left(\mathrm{~m}^{2} \mathrm{~s}^{-2}\right)$. The $\mathbf{W}_{s}$ vectors shown have magnitudes greater than the 90th percentile in the data. The maximum value of each of $\mathbf{W}_{s}, T_{\text {surf }}$, and $Z_{500}$, respectively, is shown in the top-right corner of each panel. The $T_{\text {surf }}$ and $Z_{500}$ have the same scale in every panel, where the maximum scale value is given by the second row of numbers in the top right of the first panel. The first number in the top left of the first panel is the number of extreme frost events in the composite. The red contours indicate 5 th- and 95 th-percentile values of composite $Z_{500}$ anomalies from a Monte Carlo sample of composites.

The regions of $K_{s}^{2}<0$ in Fig. 2 help to create welldefined wave channels for stationary Rossby waves. When waveguide modes are well expressed (i.e., form organized, quasi-stationary structures) in the waveguide channels, the regions of $K_{s}^{2}<0$ tend to become even more extensive than in the seasonal mean case shown here (Müller and Ambrizzi 2007; Risbey et al. 2018; Tozer et al. 2018). To capture the degree of organization and extent of the waveguide channel, we plot regions of $K_{s}^{2}<0$ in each of our frost composites.
The modes that form in the waveguide channels are often expressed as traveling wave packets that express in successive longitudinal locations around the hemisphere (Branstator 2002; Feldstein and Dayan 2008). To provide a snapshot of the propagation of such wave packets we employ the stationary wave activity flux $\mathbf{W}_{s}$ of Takaya and Nakamura $(1997,2001)$. They show that this flux is parallel to the local 3D group velocity of Rossby waves. In our case, we consider only the dominant 2D horizontal components of this flux and 
neglect the role of transient activity to focus on the stationary component. The stationary wave activity flux $\mathbf{W}_{s}$ is based on the daily climatological horizontal wind components $U$ and $V$ and perturbation streamfunction $\psi^{\prime}$ following Takaya and Nakamura (2001):

$$
\mathbf{W}_{s}=\frac{p}{2|\mathbf{U}|}\left[\begin{array}{l}
U\left(\psi_{x}^{\prime 2}-\psi^{\prime} \psi_{x x}^{\prime}\right)+V\left(\psi_{x}^{\prime} \psi_{y}^{\prime}-\psi^{\prime} \psi_{x y}^{\prime}\right) \\
U\left(\psi_{x}^{\prime} \psi_{y}^{\prime}-\psi^{\prime} \psi_{x y}^{\prime}\right)+V\left(\psi_{y}^{\prime 2}-\psi^{\prime} \psi_{y y}^{\prime}\right)
\end{array}\right],
$$

where $p$ is pressure divided by $1000 \mathrm{hPa}$ and here the pressure level is $500 \mathrm{hPa}$.

Descent of cold, dry air is a common feature of frost events. To diagnose synoptic-scale regions of ascent and descent in the flow, we use the velocity potential at $300 \mathrm{hPa} \chi_{300}$. The velocity potential describes the divergent irrotational component of the horizontal velocity field $\mathbf{V}$ via $\nabla \cdot \mathbf{V}=\nabla^{2} \chi$. Positive (negative) values of $\chi_{300}$ denote regions of upper-level convergence (divergence), which provide broad indicators of descent (ascent) of the flow.

\section{Frost events and trajectories}

Frost events at each of our stations have maximum frequency during the winter and then tail off during the spring. However, frost can occur quite late in the spring if the synoptic conditions are appropriate for producing very cold air at the surface. The number of frosts in the station record by day of year is shown for Snowtown in Fig. 3. The last frosts for the year typically occur through September and October, but can extend in to the beginning of November. The prevalence of spring frost days at each of our locations is an issue for grain damage in those regions.

The number of frosts per year at each of our station locations is highly variable. An example of this variability is shown for Merredin in Fig. 4. This series indicates multidecadal periods of enhanced frost days at the beginning of the record, a multidecadal period of reduced frost spanning the 1970s, 1980s, and 1990s, and a slight increase in frost days at the end of the record. The point here is that there is substantial interannual to multidecadal variability in spring frost frequency. One has to be careful in attributing trends in these data, however, as the variability and trend is sensitive to the definition of frost (Crimp et al. 2016). For example, a trend may be apparent for frost days defined as days $<0^{\circ} \mathrm{C}$ but not for days $<2^{\circ} \mathrm{C}$. The fact that frost frequency varies on interannual to multidecadal time scales has implications for explanations of the determinants of frost, which must account for such variability.

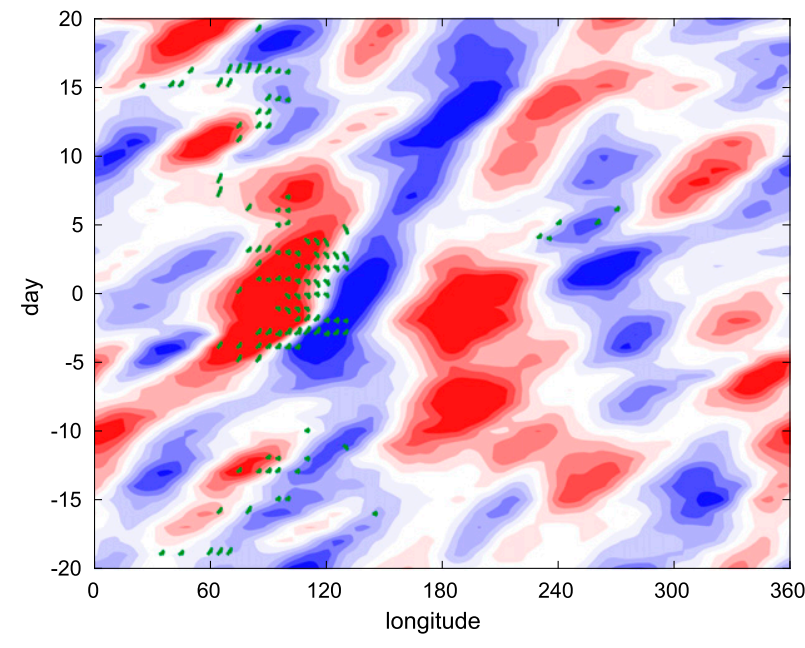

FIG. 9. Hovmöller diagram of 500-hPa geopotential height anomalies (blue for negative anomalies; red for positive anomalies) at $50^{\circ} \mathrm{S}$ for winter frost events at Merredin. The day numbers on the vertical axis correspond to the frost event day numbers. The green arrows show $\mathbf{W}_{s}$ vectors at $50^{\circ} \mathrm{S}$ that are greater than the 90 th percentile.

For each of our stations we examined the synoptic charts for many individual frost events as defined in section 2 . The synoptic features that typically accompany such events at each of our locations are the passage of a cold front in the days preceding the frost, followed by the establishment of the leading edge of a blocking high over the station region on the day of the frost. A typical such configuration is shown for frosts in the regions near Snowtown on 23 October 2016 in Fig. 5. The frosts associated with this event caused damage in wheat, barley, canola, and pulse crops, and resulted in total crop loss in some cases (Risbey et al. 2017). The blocking high is evident over the region in Fig. 5. We have also shown here back trajectories for air parcels that end up at $925 \mathrm{hPa}$ on the morning of the frost. The back trajectories seeded from a set of locations in the region are labeled "cold inflow tracks" in Fig. 5. These tracks come from the midtroposphere, well poleward and west of the surface location. The air parcels are very cold and dry, and descend down to the surface at the time of the frost event. The track of the frost trajectories from well south of the continent, moving equatorward around the blocking high are very consistent with those trajectories shown for cold outbreak events in Simmonds and Rashid (2001).

The role of the synoptic system in extreme frost events is to provide an organized and consistent trajectory for exceptionally cold, dry air to move down to the surface region at the time of the frost. To illustrate this consistency, we calculated the back parcel trajectories for all 


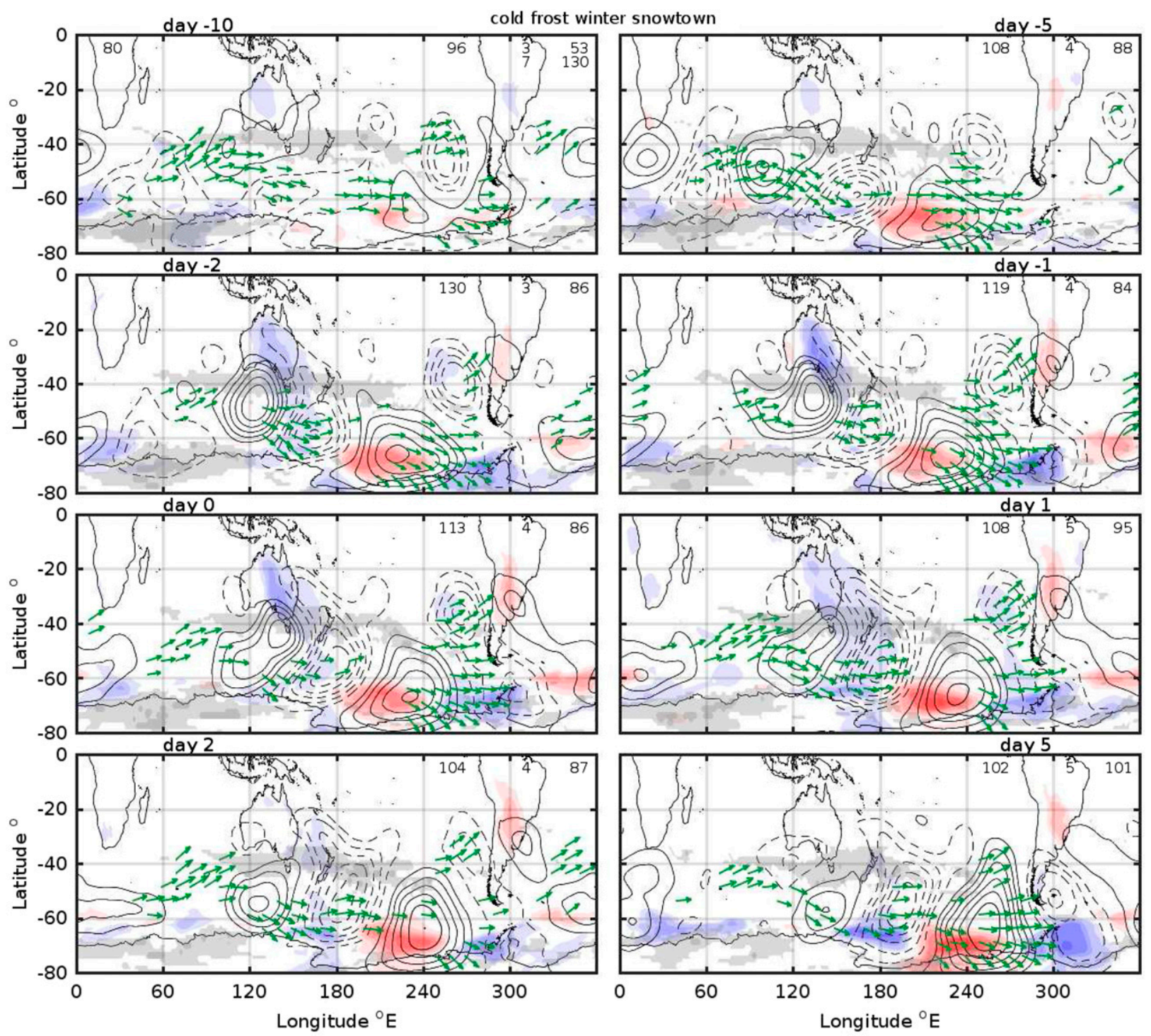

FIG. 10. As in Fig. 8, but for Snowtown.

frost events observed at Snowtown. The set of trajectories are shown in the upper left panel of Fig. 6. They all emanate from the midtroposphere in a region south and west of the area in the days before the frost event. The mean of all the trajectories is shown in the upper right panel and has a clear track from the southwest. The vertical descent of the tracks is represented in the bottom two panels in Fig. 6, which provide latitude-height and longitude-height cross sections. The mean parcel track is from between 600 and $700 \mathrm{hPa}$ down to the surface.

The parcel trajectories for frost events shown in Fig. 6 are exceptional in delivering cold, dry air to the surface region. We examined parcel trajectories for Snowtown for nonfrost days in winter and spring (not shown) and find a wide assortment of trajectory directions and an absence of trajectories from the midtroposphere well poleward of the station. The cold, dry, poleward, midtropospheric source trajectories shown in Fig. 6 are associated with virtually all Snowtown extreme frost events and are otherwise rare in parcel trajectories for other days. This behavior is also exhibited at the other stations examined here (Merredin and Gunnedah) and appears to be common to extreme frost events in Australia.

Air parcels entrained in the cold, dry descent trajectory arrive at the surface with the leading edge of a developing high pressure system. The frost event at the surface is largely localized about this leading edge region. This feature of the synoptic circulation helps to 
explain why extreme frosts at an individual location are relatively rare. The high that provides the cold, dry trajectories must form in just the right location relative to the surface station. The developing high must form immediately west and south of the station to place the station in the leading edge region of the high. We represent this configuration schematically in Fig. 7 for extreme frost events in Merredin in the far southwest of Australia. In a typical event, a front passed through the region in the day before the frost, followed by the development of the high with its leading edge in the frosted region. The cold, dry air at the surface derived from midtropospheric parcels that moved equatorward and descended in the anticyclonic branch of the developing high. Though the schematic is presented here for Merredin, it applies to each of the locations studied, which all exhibit the main feature of cold, dry descent ahead of the approaching high.

The two features of the air masses that generate the extreme frosts here are that they are both cold, and dry, and it is important to be clear about how this comes about. The air mass is cold because there is strong meridional flow ahead of the blocking high that transports cold air from the polar side of the storm track to the equatorward side of the storm track (Garfinkel and Harnik 2017; Tamarin-Brodsky et al. 2019). The air mass is dry because it descends from the dry midtroposphere down to the surface. The descent is exhibited in the parcel back trajectories and follows from conservation of potential vorticity. For the air mass moving equatorward, planetary vorticity increases with the change in latitude faster than changes in relative vorticity in the flow. This increase in the parcel vorticity is balanced by an effective decrease in stretching vorticity, resulting in descent.

The synoptic perspective taken so far helps to establish the more proximate causes of extreme frosts. However, it does not explain what controls the key synoptic system (developing high). It does not explain what controls the onset, location, and form of the high and what role that plays in the rareness of the events. To address these issues we move on to the larger-scale perspective on the frost events.

\section{Frost composites}

\section{a. Merredin}

To assess the large-scale circulation during the frost events, we generated composites of the atmospheric flow over the Southern Hemisphere for events at each location. The standard composite shown here contains contours of geopotential height anomalies $Z_{500}^{\prime}$, shaded

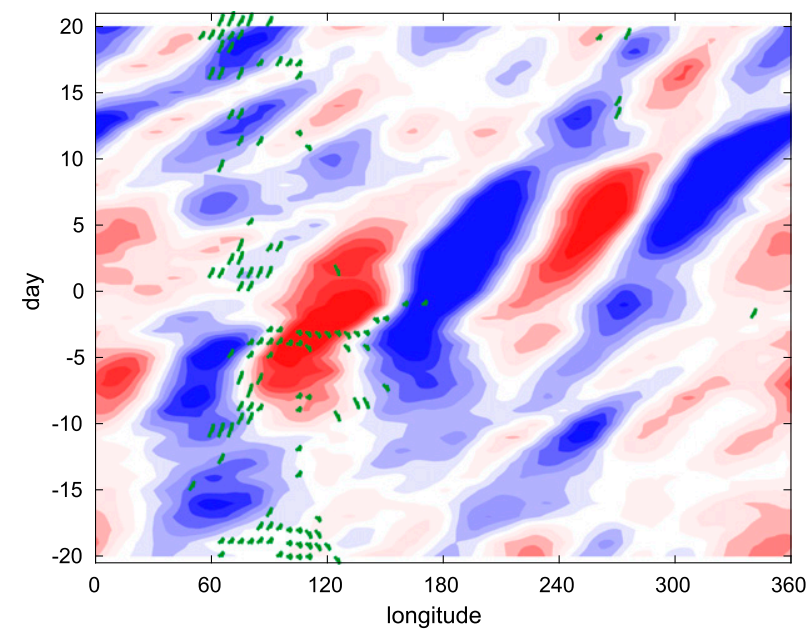

FIG. 11. As in Fig. 9, but for Snowtown.

surface temperature $T_{\text {surf }}$ anomalies, vectors for wave activity flux $\mathbf{W}_{s}$, and gray regions where $K_{s}^{2}<0$. The composites for winter frost events at Merredin are shown in Fig. 8. The main feature depicted by $Z_{500}^{\prime}$ in the period well before the event (from day -10 to day -5 ) is a SAM-like three-wave structure with highs in each of the ocean basins bounded by lower than average pressure poleward. The surface temperature anomaly for the composite has nearly continuous cold anomalies at high latitudes consistent with the SAM-like signature (Franzke et al. 2015).

In the days just prior to Merredin frost events, a clearer wave train pattern is established in $Z_{500}^{\prime}$ and persists for up to 5 days after the event. The wave train channel is marked during the event by the zonally elongated region between gray shading where $K_{s}^{2}<0$ and by the highest-magnitude $\mathbf{W}_{s}$ vectors. The $\mathbf{W}_{s}$ is particularly pronounced in the regions between each high and low in the wave train. The dominant nodes in this wave train are the blocking node that formed in the central Pacific and the block that forms off the west coast of Australia and intensifies in the days just prior to the event. This block off the west coast is the high pressure system that creates the cold, dry entrainment of air for frost events described in section 3 . The buildup of cold air at the surface associated with this approaching block is apparent in the surface temperature anomalies that span the southwest corner of Australia during the frost event.

The significance of the $Z_{500}^{\prime}$ composite in Fig. 8 is tested through a Monte Carlo procedure. For each composite we identify the number of member days in the composite. We then generate 1000 different composites, where each composite has the same number of members as our frost composites. The thousand 


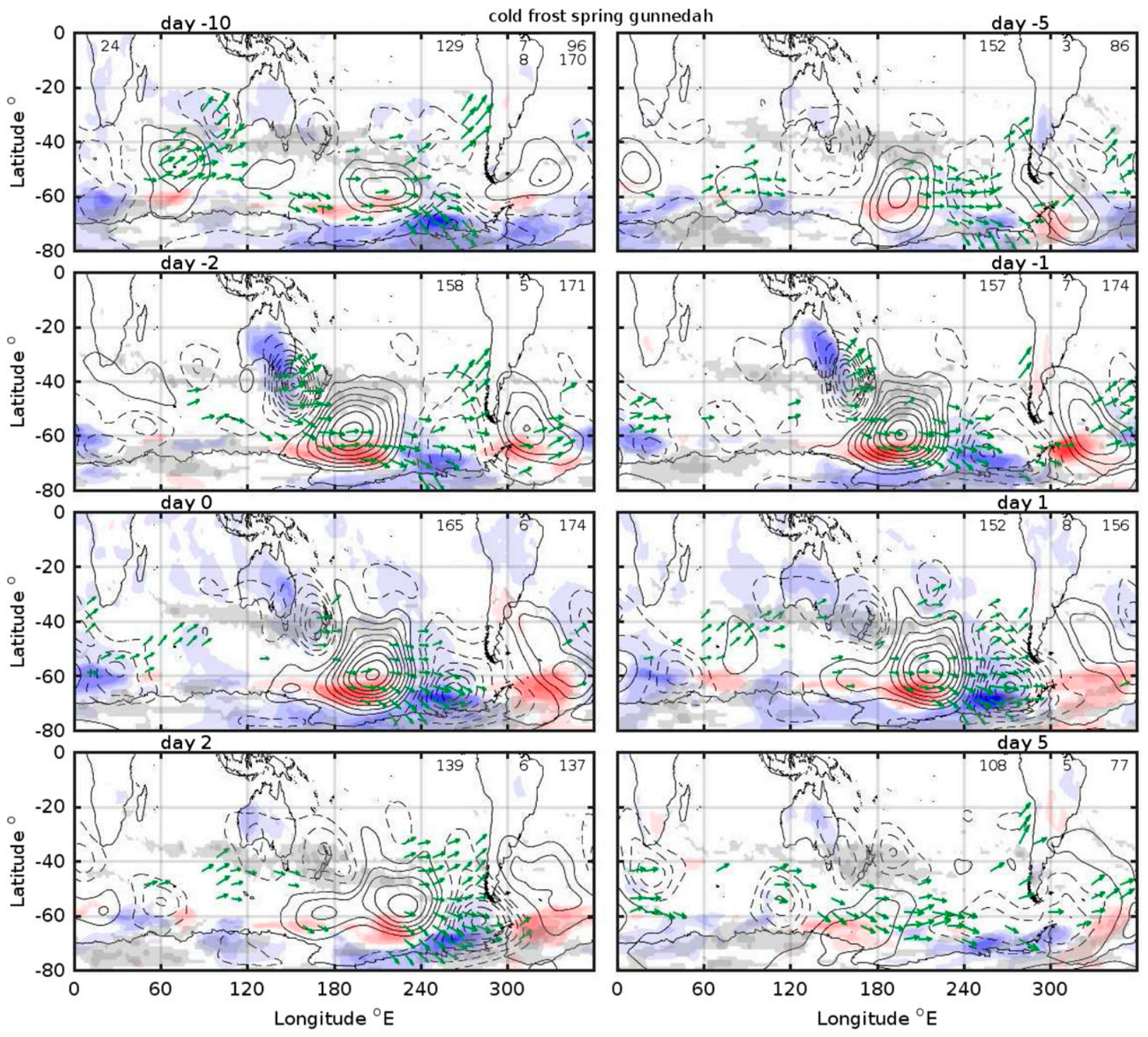

FIG. 12. As in Fig. 8, but for Gunnedah spring frost events.

composites are generated from the time series of $Z_{500}^{\prime}$ for all years for all days in the given season. Each composite is a random sample from this series (where days are selected without replacement). The means of the thousand composites are used to generate a probability distribution of composite means. We then identify representative extreme values of negative and positive composite means by the 5th- and 95th-percentile values in this distribution. We show these percentile values using contours of their value (blue contours in Fig. 8). As expected, almost all of the troughs and ridges in the wave train structures in the frost composites attain higher anomaly values than the 5th- and 95th-percentile values. This increases confidence that these structures are not likely to be simple chance outcomes of the compositing process. This result is consistent with the fact that the composite geopotential height structures form highly organized wave trains, which are prima facie unlikely to be obtained by chance. For the other locations, we do not plot the 5th- and 95th-percentile Monte Carlo contours given that they reproduce the result here that the anomaly structures are unlikely due to chance.

To obtain a more continuous picture of the evolution of the wave train that sets up during the Merredin frost events, we show a Hovmöller plot (Hovmöller 1949) of $Z_{500}^{\prime}$ and $\mathbf{W}_{s}$ at $50^{\circ} \mathrm{S}$ in Fig. 9. The central Pacific block is apparent at longitude $180^{\circ}$ from 10 days prior to the event. The blocking node that generates the frost event establishes itself near $90^{\circ} \mathrm{E}$ by 3 days prior to the event, is associated with strong fluxes of stationary wave activity, 


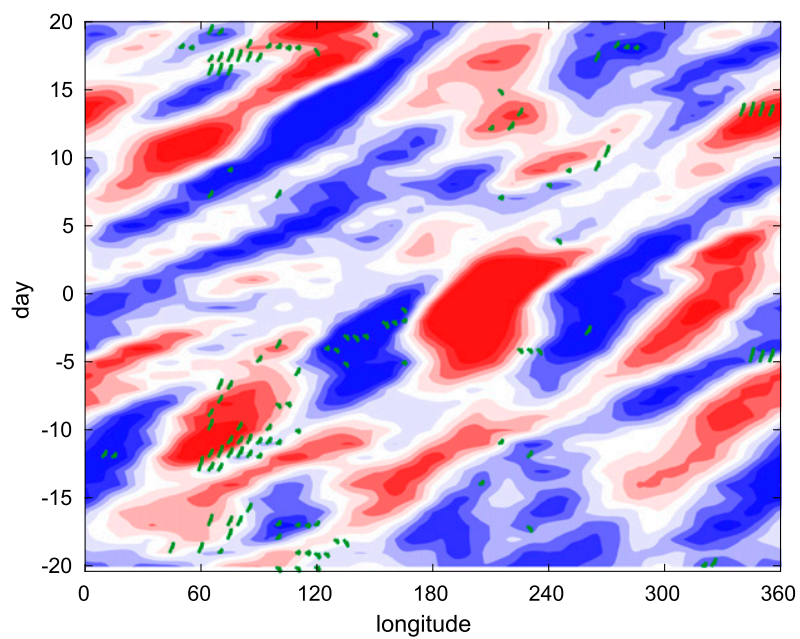

FIG. 13. As in Fig. 9, but for Gunnedah spring events.

and is quasi stationary for the next week or so. Much of the hemisphere reflects a quasi-stationary wave train during this period and then returns to moremobile flow conditions. The mobile flow conditions are characterized by higher wavenumbers and greater phase speeds than for the large-scale structures, reflecting synoptic eddies propagating more rapidly from west to east.

\section{b. Snowtown}

The composite for winter frost events at Snowtown is shown in Fig. 10. The contours of $Z_{500}^{\prime}$ again outline a wave train that forms in the polar jet channel bounded by the gray shaded regions where $K_{s}^{2}<0$. The wave train propagates to the east during the days prior and post the frost event. The organized wave train is evident in the Indian and Pacific regions prior to the event and then becomes accentuated in the Pacific and Atlantic regions after the frost event. The high associated with the frost is a blocking node of the wave train (near $120^{\circ}-140^{\circ} \mathrm{E}$ ) that intensifies in the few days just prior to the event. The intensification of the high is associated with enhanced fluxes of wave activity $\mathbf{W}_{s}$, which is also evident in Fig. 11. An examination of velocity potential, $\chi_{300}$ (not shown) at day 0 of the composite indicates the strong descent associated with this leading edge of the incoming block. The $T_{\text {surf }}$ anomalies in the region also bear the signature of the developing cold air pool at the surface. Further, there are large temperature anomalies (alternating warm and cold) off Antarctica in the Pacific and Atlantic regions, particularly after the frost event, which reflect the organized wave train structure that creates strong alternating poleward/ equatorward meridional transports.

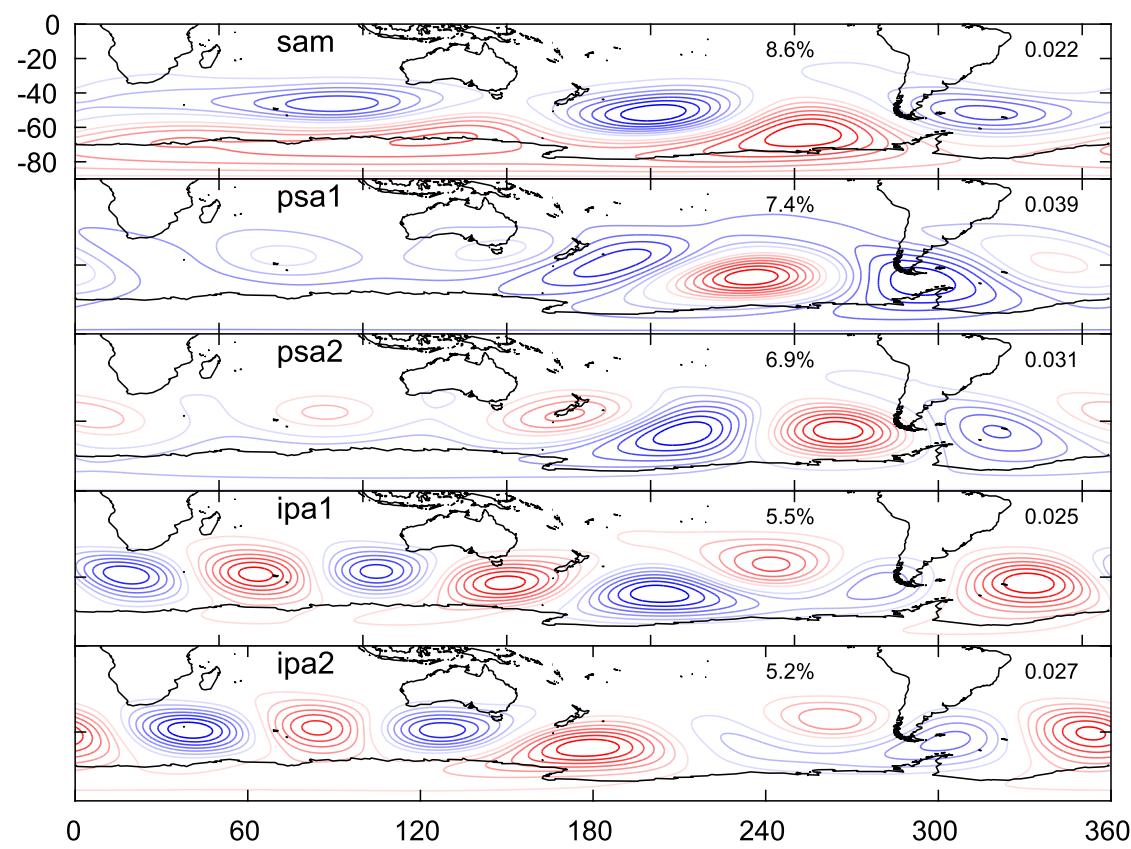

FIG. 14. EOFs $1-5$ of the 500-hPa geopotential height field for the Southern Hemisphere $\left(0^{\circ}-90^{\circ} \mathrm{S}\right)$. These patterns correspond to the indices used here for the SAM, PSA1, PSA2, IPA1, and IPA2, respectively. The numbers with percentages in the panels are the percent of variance explained by each mode, and the number in the top right of each panel is the amplitude of the maximum value in the field. 


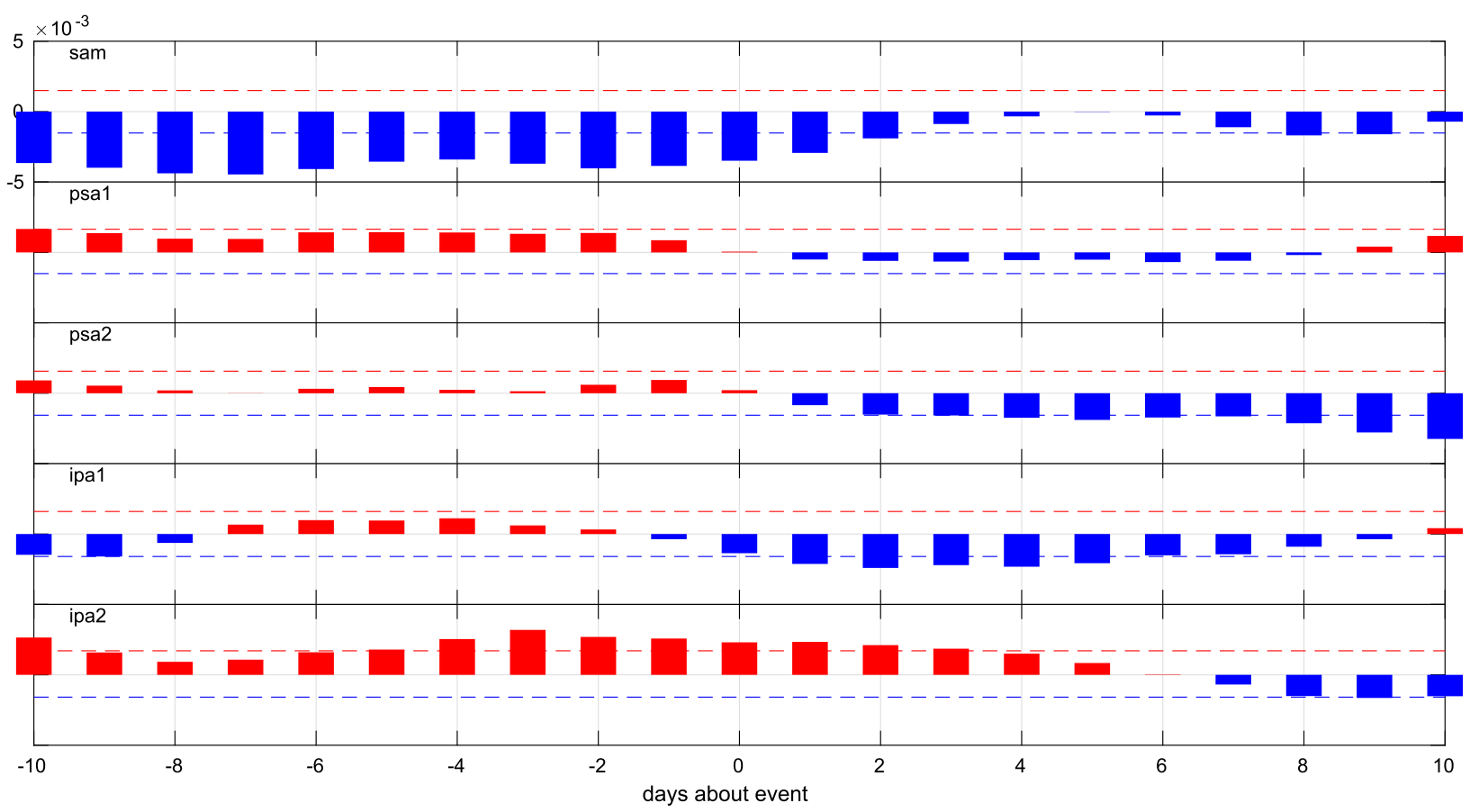

FIG. 15. Average value of each EOF mode index across Merredin frost events for SAM, PSA1, PSA2, IPA1, IPA2. Each index value is composited to produce a mean for each day about the frost event from 10 days prior to 10 days after. Positive and negative mean values are shown as red and blue bars, respectively. The dashed lines are 5th- (dashed blue) and 95th- (dashed red) percentile values from a Monte Carlo sampling of index values on randomly chosen days. Each sample contains the same number of randomly drawn days as the number of frost events. We calculate the mean of each sample and then the percentiles from all of the sample means.

The Hovmöller for Snowtown (Fig. 11) shows the features of a propagating wave train noted in the spatial (latitude-longitude) composites. The wave train is quasi-stationary in the Indian and Pacific sector (longitudes $0^{\circ}-180^{\circ}$ ) prior to the frost event, and then appears more like a traveling wave packet in the Pacific and Atlantic sectors on and after the event. By 10 days after the event, the flow returns to a more transient state.

\section{c. Gunnedah}

The composites for spring frost events at Gunnedah are shown in Fig. 12. The precursor circulation for Gunnedah shows an intense trough developing with only a very weak signature in $Z_{500}^{\prime}$ of the approaching high (which is better reflected at the surface). Once established from day -5 the trough persists as the upstream node of a wave train structure spanning the Pacific and Atlantic region. The wave train is well demarked by an extension of the gray shaded region where $K_{s}^{2}<0$. This region extends farther into the Pacific region than in its climatological mean and provides an extended wave channel for the flow. The quasistationary nature of this wave train is evident in the Hovmöller for Gunnedah (Fig. 13) where it persists largely in place from day -5 to day +2 of the event. The
Hovmöller also implies that the event is typically preceded by a traveling wave packet in the Indian sector from day -15 to day -5 that generates a block in the central Indian Ocean in the middle of this period. This block is evident in the top-left panel (day -10) of Fig. 12, where it is associated with an enhanced flux of wave activity through and downstream of the block.

\section{Hemispheric circulation modes}

The large-scale waveguide modes evident in each of the frost event composites in section 4 are reminiscent of some of the canonical, documented modes of extratropical atmospheric variability (O'Kane et al. 2016, 2017). These canonical modes have been described by Branstator (2002) as near circumglobal, wave train patterns in the waveguides formed by the extratropical jet streams. The frost waveguide modes exhibit wavenumber 3 or 4 , consistent with the maximum wavenumber $K_{s}$ for stationary Rossby waves in the polar jet waveguide. This result is also consistent with the finding of wavenumber 4 dominance for cold outbreak events in southeast Australia (Perrin and Simmonds. 1995; Simmonds and Rashid 2001). The frost waveguide modes are expressed across all or part of the hemisphere 


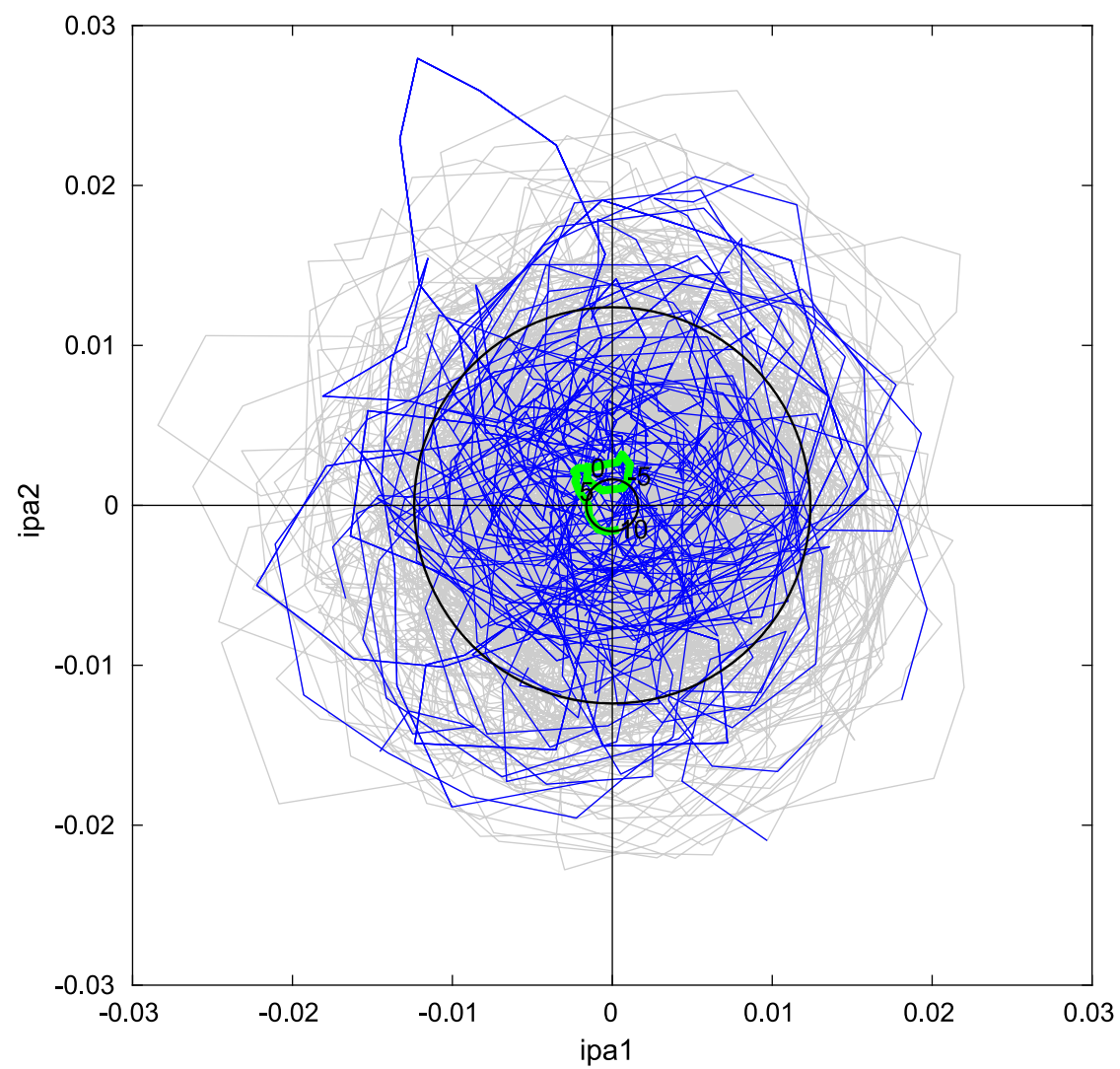

FIG. 16. Phase diagram of IPA1 vs IPA2. The gray lines correspond to IPA1 and IPA2 values across all winter days. The blue lines are for the subset of days that span from 10 days prior to 10 days after each frost event at Merredin. The thick green line shows the composite mean values of IPA1 and IPA2 over all frost events, tracking over each composite day from 10 days prior to 10 days after the events. The inner black circle represents the value of the 95 th percentile of the PSA composite mean from random samples, where each sample contains the same number of randomly drawn days as the number of frost events. The outer black circle represents the 95th-percentile values of IPA1 and IPA2 over all winter days.

in the waveguide. The question then arises whether the frost waveguide modes are manifestations of the canonical waveguide modes, or at least whether there are associations between the two.

To test the association between frost waveguide modes and the canonical modes in a consistent form, we performed an empirical orthogonal function (EOF) analysis of daily anomalies of geopotential height $Z_{500}^{\prime}$ over the Southern Hemisphere domain. The first five principal components can then be used as proxy indices for the canonical modes. The spatial patterns for these first five modes are shown in Fig. 14. The first pattern is the characteristic SAM (Thompson and Solomon 2002), with an annular signature in pressure, but also containing a three wave component in the Southern Hemisphere. The next two EOF patterns are more localized to the Pacific and South American sector of the polar waveguide and denote the Pacific-South America
(PSA) pattern (Mo and Ghil 1987; Lau et al. 1994). These are usually denoted PSA1 and PSA2 to reflect their association. They explain similar amounts of variance and are in approximate zonal quadrature. To be sure, these EOF/principal-component modes are not purely in quadrature since they exhibit cross coherence of less than 1 over synoptic frequencies. These modes together represent both propagating and quasi-stationary aspects of the flow variability. The next two modes are similarly associated in that they too explain similar amounts of variance and are in approximate zonal quadrature. These two modes have amplitude through the entire polar waveguide, though with maximum expression in the Indian Ocean sector. We denote these modes Indian Pacific Atlantic (IPA) 1 and 2 (O'Kane et al. 2017; Tozer et al. 2018).

Note that the extratropical circulation modes such as the EOF patterns described above are not statistically 


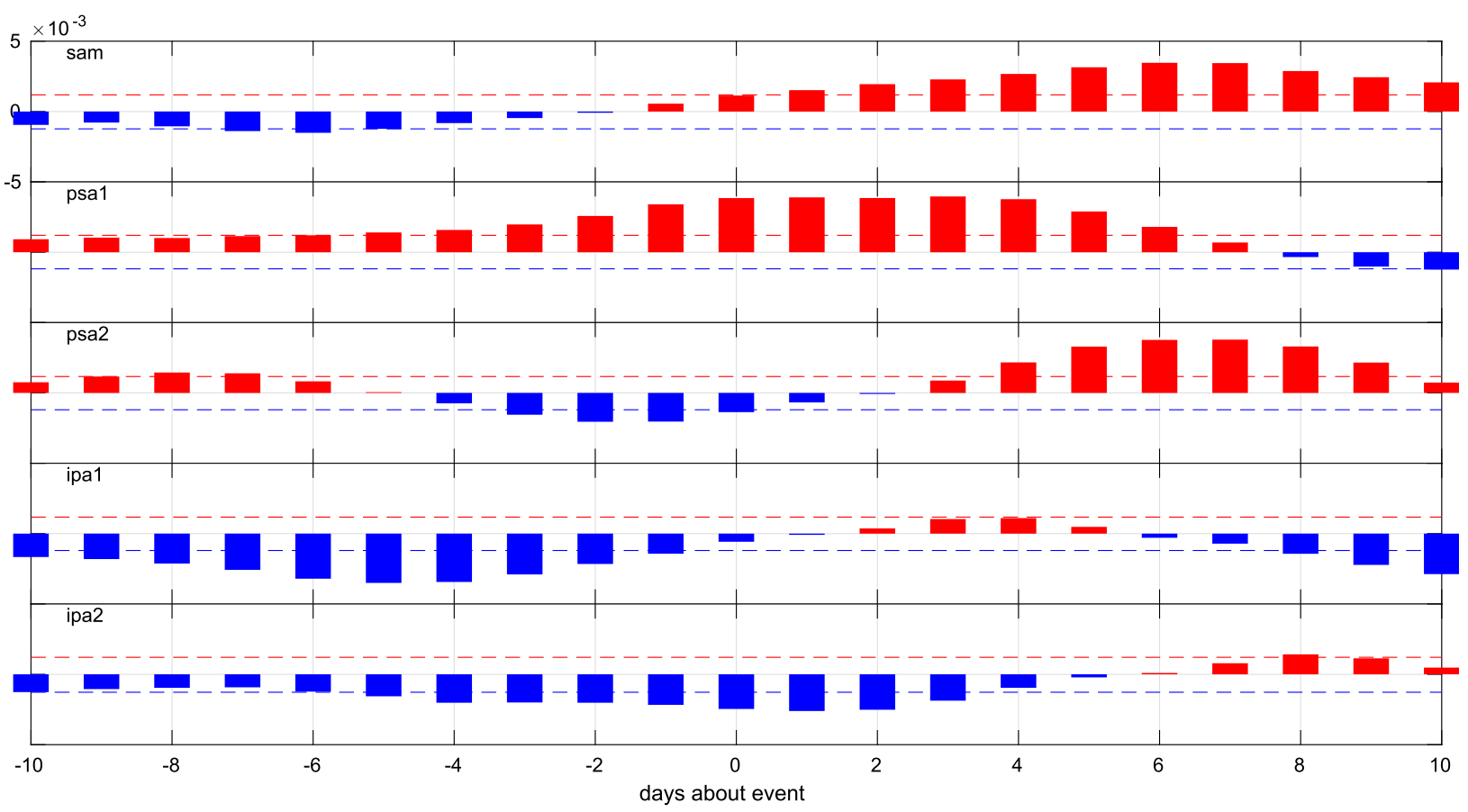

FIG. 17. As in Fig. 15, but for Snowtown frost events.

robust because of the limited sampling of atmospheric data (North et al. 1982), the very large degree of freedom in the data, and the methodological assumptions of stationarity which are not satisfied in real data (Risbey et al. 2015). Confidence in the patterns is increased when similar results are derived from different methods. In the case of the PSA pattern, broadly similar patterns and results are obtained using EOF analysis (Mo and Ghil 1987), cluster analysis (O'Kane et al. 2016), Fourier analysis (Irving and Simmonds 2016), and singular spectral analysis (O'Kane et al. 2017). For the IPA pattern, EOF analysis (O'Kane et al. 2017), cluster analysis (O'Kane et al. 2016), and singular spectral analysis (O'Kane et al. 2017) yield similar patterns.

The PSA and IPA EOF modes can reflect waveguide modes of variability since their nodes (Fig. 14) exhibit a wave-4 pattern and sit primarily in the polar waveguide channel characterized by stationary wavenumbers $2-4$ in Fig. 2. The EOF patterns are time-invariant and may capture typical expressions of the waveguide modes at best. With this limitation in mind, we refer to the PSA and IPA here as the waveguide EOF modes. The way in which SAM is defined here, as the leading pattern of variability also allows it to capture some expression in the waveguide via the wave- 3 component reflected in the resulting EOF. However, we primarily think of SAM as an annular mode (Lorenz 1951) and differentiate it from the waveguide EOF modes (PSA; IPA) by the signature of high/low pressure in annular form, which is not present for the waveguide EOF modes.

To provide a quantitative measure of the relationship between frost events and the canonical EOF modes, we provide composite means of the magnitudes of each EOF mode over the days prior, during, and after the frost events at each location. This relationship is shown for the EOF modes and Merredin frost events in Fig. 15. We might infer some relationship between the EOF mode and the frost events when the composite mean amplitude for the mode is consistently (from one day to the next in the event life cycle) more extreme than the 5th- (for negative values of the index) or 95th- (for positive values) percentile values of the index composite. In the early lead up (from at least day -10) to frost events in Merredin this condition is satisfied for the SAM index, which is consistently strongly negative. This result showing a strong projection of Merredin frost on the SAM mode is consistent with the spatial pattern of the Merredin frost composite at day -10 in Fig. 8, which shows a $Z_{500}^{\prime}$ anomaly pattern that is nearly identical (with opposite sign) to the EOF pattern for SAM in Fig. 14.

Closer to the Merredin frost event, from day -3 on, the waveguide EOF modes are expressed in turn in Fig. 15, with IPA2 from days -4 to +1 , IPA1 from days +1 to +6 , and then PSA2 from day +8 . This response is also consistent with the spatial frost event $Z_{500}^{\prime}$ 


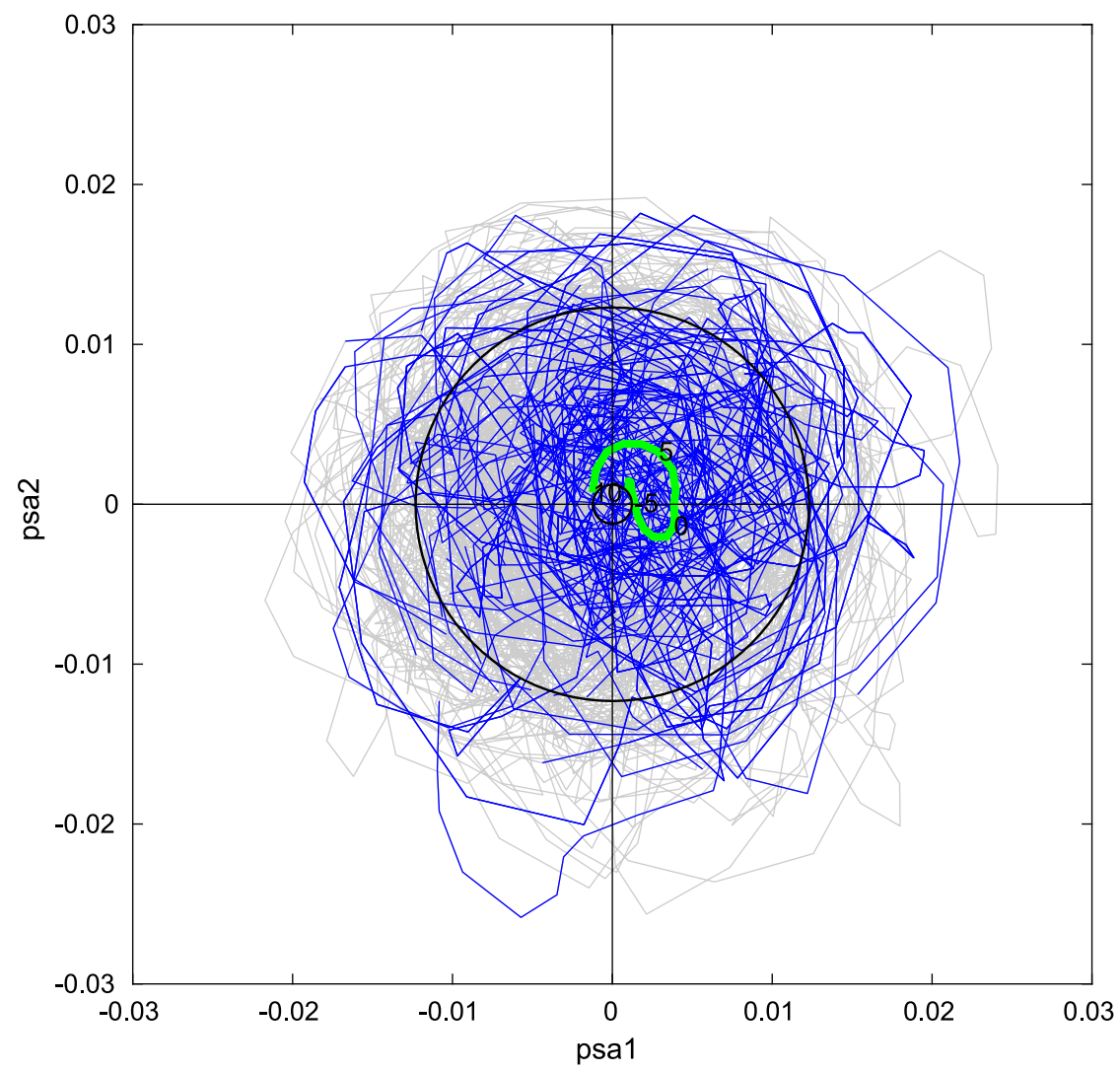

FIG. 18. As in Fig. 16, but for Snowtown PSA modes.

composites in Fig. 8, which exhibit wave train structures during this period.

The above results suggest that Merredin frost events do project on to the EOF modes. For example, the IPA is expressed about Merredin frost events. The magnitude of the IPA is consistently in its most extreme ventile when Merredin frost occurs. To see how often extreme values of the IPA correspond to Merredin frosts, we show the phase diagram for IPA1 and IPA2 in Fig. 16. All IPA events are indicated by gray lines on the phase diagram, while those corresponding to Merredin frost events are shown by blue lines. It is clear that Merredin frost events compose only a subset of the highest-amplitude, longer-lived IPA events, though they do make up some of the more notable events in the record.

The composite of EOF modes values for frost events at Snowtown is shown in Fig. 17. In the period leading up to the frost event (from 10 days prior to the event) the amplitude of the IPA mode is particularly strong. The IPA has high amplitude in the Indian Ocean sector, so this result is consistent with the stationary wave train present in the Indian Ocean region prior to the event. That wave train is evident in the spatial composite for day -5 in Fig. 10 and in the Hovmöller for Snowtown (Fig. 11). In the period from 2 days prior to 9 days after the event the PSA mode has large amplitude, first in PSA1 and then in PSA2. This result is also evident by the wave train in the Pacific region in the spatial composite and the Hovmöller. The phase diagram for the PSA (Fig. 18) shows that Snowtown frost events are a subset of PSA events but constitute some of the largeramplitude, longer-lived events (long blue arcs near the outer edge of the set of PSA trajectories). The trajectory for the composite values of PSA magnitude over frost event days is given by the green line, which emerges well beyond the 95th-percentile radius before the day of the event and well after, traversing through the top-right quadrant. The trajectory reflects propagation of the PSA mode during the frost event, consistent with the nonzero group velocity for the mode evident in the Hovmöller.

The composite of EOF modes through the frost event for Gunnedah is shown in Fig. 19. The IPA mode is strongly expressed and significant from day -8 to day -3 , followed by the expression of the PSA mode from day -3 to day +3 . This result is consistent with the Hovmöller for Gunnedah (Fig. 13) which indicates a traveling wave train in the Indian Ocean sector prior to 


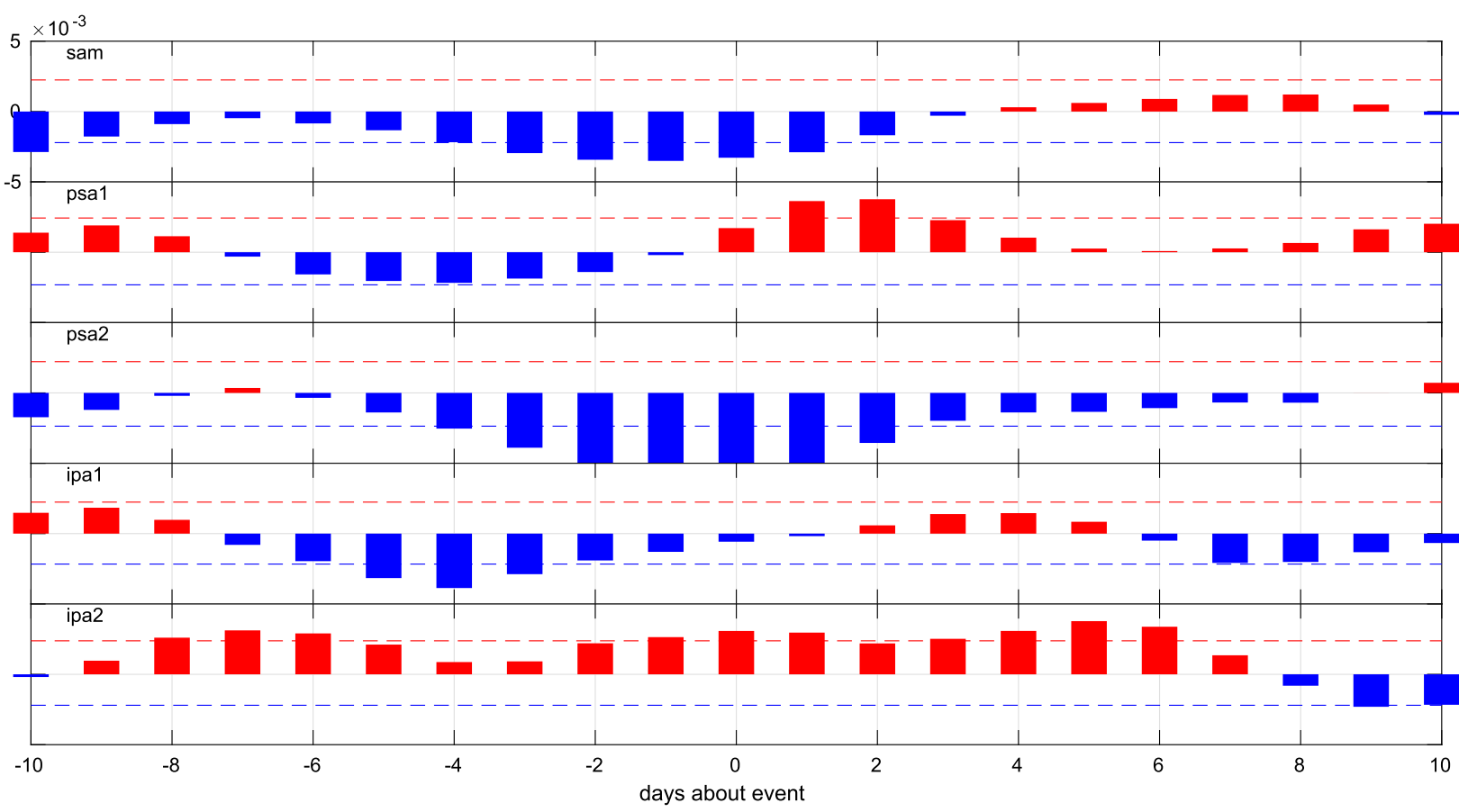

FIG. 19. As in Fig. 15, but for Gunnedah spring frost events.

day -3 , followed by a quasi-stationary wave train in the Pacific sector from day -3 to day +3 . The spatial composite (Fig. 12) also reflects the wave train in the Pacific sector during these days, which has dissipated by day +5 . The phase diagram for the PSA mode for Gunnedah (Fig. 20) also shows the strong expression of the PSA via the significant trajectory of the green composite mean line in the days just prior to and just after the frost event.

\section{Summary and conclusions}

We return now to some of the questions raised at the outset as to why extreme frost events occur, why they are rare at a given location, and why their statistics are so variable from year to year. The answers to these questions lie in both the synoptic and large scales, and in the links between them. To draw out these associations we provide a schematic of the flow for one of our stations, Snowtown, in Fig. 21. In the atmospheric flow for the day prior to the frost event a pool of cold air is evident at the surface spanning a subsynoptic region with a radius of a few hundred kilometers around the station. This cold pool is at the leading edge of the blocking high approaching the station. We know that this high constitutes a block because it is dynamically generated as a node of the wave train that appears in the midtroposphere (in the upper panel), and it is quasistationary during the period of the frost (before and after).
The blocking high is able to generate colder minimum temperatures than more transient highs or those that comprise the shallow (in depth) subtropical ridge. All highs generate weak, broad descent over their characteristic spatial scales, which are the largest synoptic structures for subtropical ridge highs and synoptic-eddy scale for blocking highs. However, this weak synopticscale descent does not generate extreme frosts. The weak descent results in clear skies, leading to strong radiative heat loss at night and cold morning temperatures. However, the radiative process alone is not enough to generate extreme frosts. If it were, they would be much more common (because there are many transient and subtropical ridge highs traversing the region every winter and spring) and the region of the cold pool would be synoptic scale, spanning the entire region of the high. Contrary to this, the cold pools associated with extreme frosts are subsynoptic in scale and they are rare.

The blocking high can be further differentiated from the transient and subtropical highs in that it draws more heavily on the organized dynamics of the flow. The blocking highs related to extreme frost in this study are all part of organized, large-scale quasi-stationary wave trains. Garfinkel and Harnik (2017) show that by being embedded in the jet stream wave train, the blocking high provides meridional transport over the storm track region with its characteristic large meridional temperature gradients (Gitelman et al. 1997). This mechanism generates large cold anomalies on the equatorward side of 


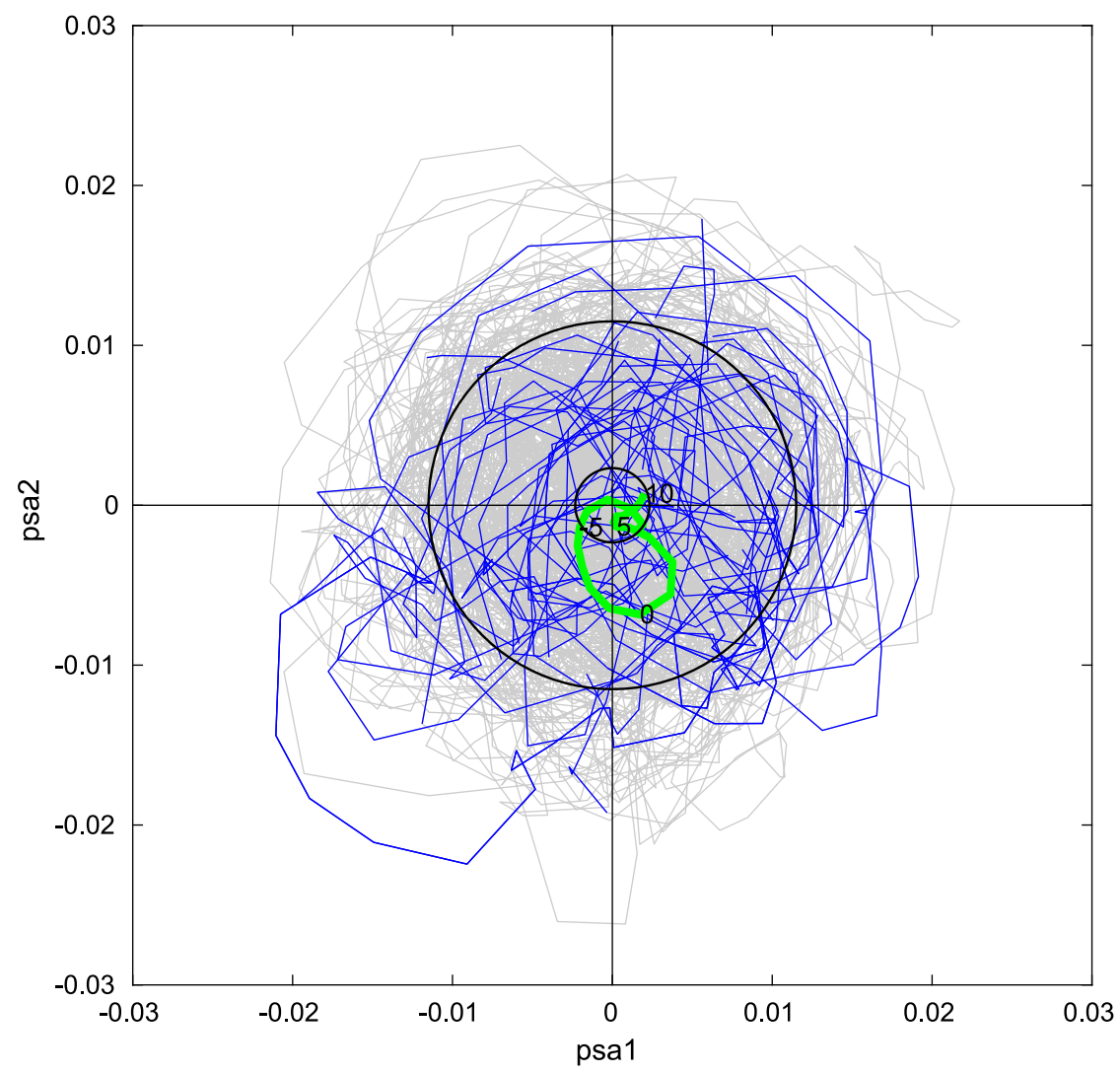

FIG. 20. As in Fig. 16, but for Gunnedah spring PSA modes.

the storm track (Garfinkel and Harnik 2017) where our stations are located. The blocking high has more coherence through the depth of the troposphere and it is actively maintained by baroclinic and barotropic instabilities (Frederiksen 1982) and draws upon the wave activity in the wave train in which it is embedded (green vectors in Fig. 21) (Nakamura 1994; Nakamura et al. 1997). Enhanced wave activity tends to coincide with the formation of coherent nodes in the wave train patterns.

These dynamical features of blocks allow them to have more persistence and to generate regions of more concentrated horizontal and vertical velocity. The vertical velocity signature is particularly enhanced (as the rapid descent) on the leading edge of the approaching block, providing a dynamical source for the very cold air pool. This dynamical process for the generation of the cold air pool is consistent with the subsynoptic scale of the pool. Further, blocks are much rarer than transient highs or subtropical highs at any given station, which makes them a much better candidate for explaining the rarity of extreme frosts.

Blocking highs play a clear role in extreme frost events in Merredin and Snowtown, but less so for Gunnedah, where the high is weaker and there is an intense, persistent trough. In this case, the trough is quasi stationary before and during the event and also brings about dynamically induced cold, dry descent of parcels from the midtroposphere to the south, down to the surface. The common feature of all of the extreme frost cases is the dynamically induced cold dry descent. The source of this dynamical organization lies in the larger-scale, quasi-stationary modes in which the synoptic-scale trough and ridge/block is embedded.

The large-scale waveguide modes associated with each of the extreme frost regions considered here have some features in common, and some differences. They are all waveguide modes in that they occur in the waveguide channel created by the polar jet. They all feature an enhanced demarcation of that channel during frost events, with wavenumber 3 or 4 organized wave train structures consistent with the maximum wavenumber for stationary Rossby waves in the channel. They all exhibit a quasi-stationary period for the wave train, with that period lasting on the order of a week. They all attain significant projections on to the canonical EOF modes of extratropical variability, the IPA and PSA. 


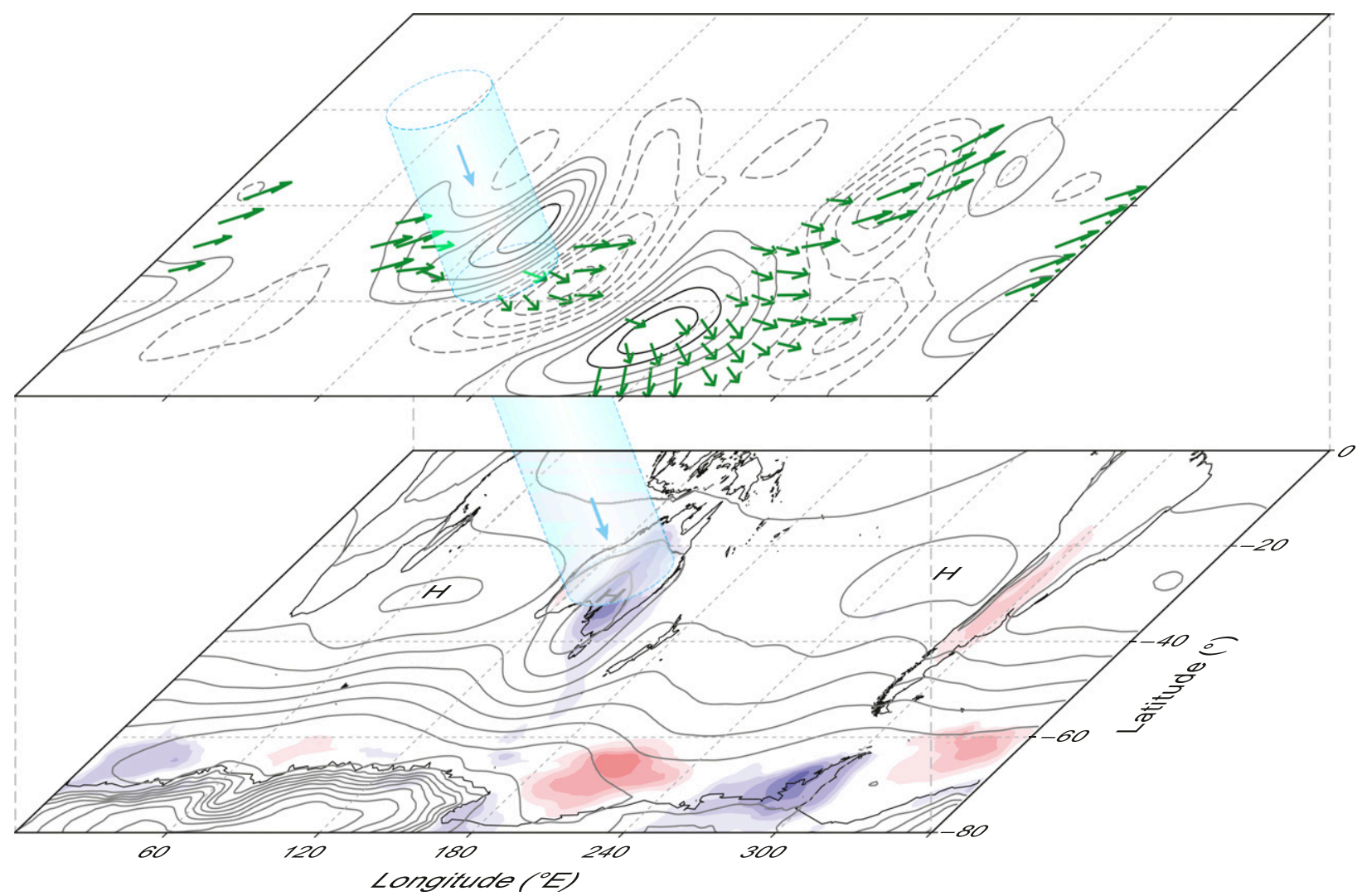

FIG. 21. Schematic of frost event at Snowtown. The fields here are for the composite on the day prior to the frost event. The surface layer shows mean sea level pressure (contours) and temperature anomalies (shaded: blue negative and red positive). The upper layer shows $Z_{500}^{\prime}$ (contours: solid positive and dashed negative) and $\mathbf{W}_{s}$ (green vectors). The cyan-shaded cylinder between layers indicates the descent of cold air.

The waveguide structures for the regions do differ in the way the waveguide events appear to set up (Simmonds and Richter 2000). For Merredin events, a SAM-like structure sets up well in advance of the event, from about 10 days prior to the event. Just before the event, a circumglobal-scale quasi-stationary wave train sets up and persists for about a week. For Snowtown frost events, a quasi-stationary wave train sets up in the Indian and Pacific sectors for the week prior to the event, and then takes on the form of a traveling wave train from the event onward for a week. For Gunnedah frost events the sequence of quasi-stationary and traveling behavior is reversed. That is, there is a traveling wave train in the Indian to Pacific sector in the 2 weeks preceding the event, which then becomes quasi stationary in the Pacific sector for the week centered on the event. In short, there are differences in the sectoral or circumglobal extent of the waveguide modes, and differences in where and when the mode appears as quasi stationary or traveling. These differences occur for a selection of stations across southern Australia (spanning roughly a "synoptic" spatial scale), indicating the diversity of expression of waveguide modes.
The frost waveguide modes here control the location and persistence of the blocks generating the frost events. An understanding of these waveguide modes is therefore critical to developing a fuller explanation of the factors controlling the variability of extreme frost events. We have not performed a causal analysis of the variability of the waveguide modes here, but we note that they exhibit considerable variability on all time scales (O'Kane et al. 2017), including longer (multidecadal) time scales (O'Kane et al. 2013, 2016). The multi- and longtime-scale variability of the waveguide modes is consistent with the multi- and long-time-scale variability exhibited for extreme frost events at a location.

The circulation structures associated with frost events exhibit periods during their flow life cycle of strong projection onto the canonical extratropical modes of variability in the Southern Hemisphere: SAM, PSA, and IPA. Frost event circulation structures constitute some of the very high amplitude, long-lived episodes of the PSA and IPA modes, although they are only a subset of such events for these modes. The PSA and IPA only sometimes exhibit high-amplitude organization and coherent waveguide structure. Extreme frost events in 
Australia (and elsewhere) coincide with some of these organized waveguide events. The challenge remains to more fully determine the factors leading to such organization and its variability.

For the frost events examined here, some of the organized large-scale waveguide modes precede the actual frost event at our stations by up to two weeks. While that might be useful from the perspective of weather forecasts of frost events, the difficulty remains of forecasting the emergence of the key blocking nodes within the large-scale structure and their timing and location. The relationship between frost and large-scale modes may offer potential for seasonal-scale forecasting. If one can forecast changes in the preferred states or regimes of these large-scale modes (in response to more predictable changes in the forcing of the flow), then that may have implications for the likelihood of frost events in a region. The control of frost variability by waveguide modes also has implications for projections of frost in climate change studies. To have confidence in the projections of frost changes, one needs to show that the waveguide modes (and the processes that control their variability) are well represented in the models.

Acknowledgments. This work was supported by the CSIRO Decadal Climate Forecasting Project and the Australian Grains Research and Development Corporation. The surface temperature data used here are from the Australian Bureau of Meteorology and are available online (http://www.bom.gov.au/climate/change/acornsat/). The reanalysis data used for this study are from the Japanese 55-year Reanalysis (JRA-55) project carried out by the Japan Meteorological Agency (JMA; http:// jra.kishou.go.jp/JRA-55/).

\section{REFERENCES}

Ambrizzi, T., B. Hoskins, and H. Hsu, 1995: Rossby wave propagation and teleconnection patterns in the Austral winter. J. Atmos. Sci., 52, 3661-3672, https://doi.org/10.1175/ 1520-0469(1995)052<3661:RWPATP $>2.0$.CO;2.

Ashcroft, L., A. Pezza, and I. Simmonds, 2009: Cold events over southern Australia: Synoptic climatology and hemispheric structure. J. Climate, 22, 6679-6698, https://doi.org/10.1175/ 2009JCLI2997.1.

Avissar, R., and Y. Mahrer, 1988: Mapping frost-sensitive areas with a three-dimensional local-scale numerical model. Part I. Physical and numerical aspects. J. Appl. Meteor. Climatol., 27, 414-426, https://doi.org/10.1175/1520-0450(1988)027<0400: MFSAWA $>2.0 . \mathrm{CO} ; 2$

Barlow, K., B. Christy, G. O'Leary, P. Riffkin, and J. Nuttall, 2015: Simulating the impact of extreme heat and frost events on wheat crop production: A review. Field Crops Res., 171, 109_ 119, https://doi.org/10.1016/j.fcr.2014.11.010.

Branstator, G., 2002: Circumglobal teleconnections, the jet stream waveguide, and the North Atlantic Oscillation. J. Climate, 15,
1893-1910, https://doi.org/10.1175/1520-0442(2002)015<1893: CTTJSW $>2.0 . \mathrm{CO} ; 2$.

Crimp, S., D. Gobbett, P. Kokic, U. Nidumolu, M. Howden, and N. Nicholls, 2016: Recent seasonal and long-term changes in southern Australian frost occurrence. Climatic Change, 139, 115-128, https://doi.org/10.1007/s10584-016-1763-5.

Feldstein, S., and U. Dayan, 2008: Circumglobal teleconnections and wave packets associated with Israeli winter precipitation. Quart. J. Roy. Meteor. Soc., 134, 455-467, https://doi.org/ 10.1002/qj.225.

Flohr, B., J. Hunt, J. Kirkegaard, and J. Evans, 2017: Water and temperature stress define the optimal flowering period for wheat in south-eastern Australia. Field Crops Res., 209, 108119, https://doi.org/10.1016/j.fcr.2017.04.012.

Franzke, C., T. O'Kane, D. Monselesan, J. Risbey, and I. Horenko, 2015: Systematic attribution of observed Southern Hemisphere circulation trends to external forcing and internal variability. Nonlinear Processes Geophys., 22, 513-525, https:// doi.org/10.5194/npg-22-513-2015.

Frederiks, T., J. Christopher, M. Sutherland, and A. Borrell, 2015: Post-head-emergence frost in wheat and barley: Defining the problem, assessing the damage, and identifying resistance. J. Exp. Bot., 66, 3487-3498, https://doi.org/10.1093/jxb/erv088.

Frederiksen, J., 1982: A unified three-dimensional instability theory of the onset of blocking and cyclogenesis. J. Atmos. Sci., 39, 969-982, https://doi.org/10.1175/1520-0469(1982)039<0969: AUTDIT $>2.0 . \mathrm{CO} ; 2$.

Garfinkel, C., and N. Harnik, 2017: The non-Gaussianity and spatial asymmetry of temperature extremes relative to the storm track: The role of horizontal advection. J. Climate, 30, 445464, https://doi.org/10.1175/JCLI-D-15-0806.1.

Gitelman, A., J. Risbey, R. Kass, and R. Rosen, 1997: Trends in the surface meridional temperature gradient. Geophys. Res. Lett., 24, 1243-1246, https://doi.org/10.1029/97GL01154.

Harnik, N., G. Messori, R. Caballero, and S. Feldstein, 2016: The circumglobal North American wave pattern and its relation to cold events in eastern North America. Geophys. Res. Lett., 43, 11 015-11 023, https://doi.org/10.1002/2016GL070760.

Hoskins, B., and T. Ambrizzi, 1993: Rossby wave propagation on a realistic longitudinally varying flow. J. Atmos. Sci., 50, 16611671, https://doi.org/10.1175/1520-0469(1993)050<1661: RWPOAR $>2.0 . \mathrm{CO} ; 2$.

Hovmöller, E., 1949: The trough and ridge diagram. Tellus, 1 (2), 62-66, https://doi.org/10.3402/tellusa.v1i2.8498.

Irving, D., and I. Simmonds, 2016: A new method for identifying the Pacific South American pattern and its influence on regional climate variability. J. Climate, 29, 6109-6125, https:// doi.org/10.1175/JCLI-D-15-0843.1.

Kalnay, E., and Coauthors, 1996: The NCEP/NCAR 40-Year Reanalysis Project. Bull. Amer. Meteor. Soc., 77, 437-471, https:// doi.org/10.1175/1520-0477(1996)077<0437:TNYRP>2.0.CO;2.

Kobayashi, S., and Coauthors, 2015: The JRA-55 Reanalysis: General specifications and basic characteristics. J. Meteor. Soc. Japan, 93, 5-48, https://doi.org/10.2151/jmsj.2015-001.

Krishnamurti, T., M. Tewari, D. Chakraborty, J. Marengo, P. S. Dias, and P. Satyamurty, 1999: Downstream amplification: A possible precursor to major freeze events over southeastern Brazil. Wea. Forecasting, 14, 242-270, https://doi.org/10.1175/ 1520-0434(1999)014<0242:DAAPPT>2.0.CO;2.

Lau, K., P. Sheu, and I. Kang, 1994: Multiscale low-frequency circulation modes in the global atmosphere. J. Atmos. Sci., 51, 1169-1193, https://doi.org/10.1175/1520-0469(1994)051<1169: MLFCMI $>2.0 . \mathrm{CO} ; 2$. 
Lorenz, E., 1951: Seasonal and irregular variations of the Northern Hemisphere sea-level pressure profile. J. Meteor., 8, 52-59, https://doi.org/10.1175/1520-0469(1951)008<0052: SAIVOT $>2.0 . \mathrm{CO} ; 2$.

McIntosh, P., M. Pook, J. Risbey, S. Lisson, and M. Rebbeck, 2007: Seasonal climate forecasts for agriculture: Towards better understanding and value. Field Crops Res., 104, 130-138, https://doi.org/10.1016/j.fcr.2007.03.019.

Mo, K., and M. Ghil, 1987: Statistics and dynamics of persistent anomalies. J. Atmos. Sci., 44, 877-902, https://doi.org/10.1175/ 1520-0469(1987)044<0877:SADOPA > 2.0.CO;2.

Müller, G., and T. Ambrizzi, 2007: Teleconnection patterns and Rossby wave propagation associated with generalized frosts over southern South America. Climate Dyn., 29, 633-645, https://doi.org/10.1007/s00382-007-0253-x.

__ and G. Berri, 2007: Atmospheric circulation associated with persistent generalized frosts in central-southern South America. Mon. Wea. Rev., 135, 1268-1289, https://doi.org/ 10.1175/MWR3344.1.

- , and - 2012: Atmospheric circulation associated with extreme generalized frosts persistence in central-southern South America. Climate Dyn., 38, 837-857, https://doi.org/10.1007/ s00382-011-1113-2.

_- R. Compagnucci, M. Nunez, and A. Salles, 2003: Surface circulation associated with frost in the wet Pampas. Int J. Climatol., 23, 943-961, https://doi.org/10.1002/joc.907.

- T. Ambrizzi, and M. Nunez, 2005: Mean atmospheric circulation leading to generalized frosts in central southern South America. Theor. Appl. Climatol, , 82, 95-112, https://doi.org/ 10.1007/s00704-004-0107-y.

,$- \ldots$, and S. Ferraz, 2008: The role of the observed tropical convection in the generation of frost events in the southern cone of South America. Ann. Geophys., 26, 1379-1390, https:// doi.org/10.5194/angeo-26-1379-2008.

Nakamura, H., 1994: Rotational evolution of potential vorticity associated with a strong blocking flow configuration over Europe. Geophys. Res. Lett., 21, 2003-2006, https://doi.org/ 10.1029/94GL01614.

_ M. Nakamura, and J. Anderson, 1997: The role of high- and low-frequency dynamics in blocking formation. Mon. Wea. Rev., 125, 2074-2093, https://doi.org/10.1175/1520-0493(1997) $125<2074$ :TROHAL $>2.0$. CO; 2 .

Newman, M., and P. Sardeshmukh, 1998: The impact of the annual cycle on the North Pacific/North American response to remote low-frequency forcing. J. Atmos. Sci., 55, 1336-1353, https://doi.org/10.1175/1520-0469(1998)055<1336: TIOTAC $>2.0 . \mathrm{CO} ; 2$

North, G., T. Bell, and R. Cahalan, 1982: Sampling errors in the estimation of empirical orthogonal functions. Mon. Wea. Rev., 110, 699-706, https://doi.org/10.1175/1520-0493(1982)110<0699: SEITEO $>2.0 . \mathrm{CO} ; 2$.

O'Kane, T., J. Risbey, C. Franzke, I. Horenko, and D. Monselesan, 2013: Changes in the metastability of the midlatitude Southern Hemisphere circulation and the utility of nonstationary cluster analysis and split-flow blocking indices as diagnostic tools. J. Atmos. Sci., 70, 824-842, https://doi.org/10.1175/ JAS-D-12-028.1.

,,-- D. Monselesan, I. Horenko, and C. Franzke, 2016: On the dynamics of persistent states and their secular trends in the waveguides of the Southern Hemisphere troposphere. Climate Dyn., 46, 3567-3597, https://doi.org/10.1007/s00382-015-2786-8.

_- D. Monselesan, and J. Risbey, 2017: A multiscale reexamination of the Pacific-South American pattern.
Mon. Wea. Rev., 145, 379-402, https://doi.org/10.1175/ MWR-D-16-0291.1.

Perrin, G., and I. Simmonds, 1995: The origin and characteristics of cold air outbreaks over Melbourne. Aust. Meteor. Mag., 44, 41-59.

Pezza, A., and T. Ambrizzi, 2005: Dynamical conditions and synoptic tracks associated with different types of cold surge over tropical South America. Int. J. Climatol., 25, 215-241, https:// doi.org/10.1002/joc.1080.

Pook, M., J. Risbey, P. McIntosh, C. Ummenhofer, A. Marshall, and G. Meyers, 2013: The seasonal cycle of blocking and associated physical mechanisms in the Australian region and relationship with rainfall. Mon. Wea. Rev., 141, 4534-4553, https://doi.org/10.1175/MWR-D-13-00040.1.

Risbey, J., M. Pook, and P. McIntosh, 2013: Spatial trends in synoptic rainfall in southern Australia. Geophys. Res. Lett., 40, 3781-3785, https://doi.org/10.1002/grl.50739.

, T. O'Kane, D. Monselesan, C. Franzke, and I. Horenko, 2015: Metastability of Northern Hemisphere teleconnection modes. J. Atmos. Sci., 72, 35-54, https://doi.org/10.1175/JASD-14-0020.1.

—, P. Hayman, B. Biddulph, M. Faulkner, and M. Pook, 2017: Damaging spring frosts a result of blocking highs. Aust. Grain, March/April, 32-33, http://ausgrain.com.au/Back\%20Issues/ 266magrn17/damaging_spring_frosts.pdf.

—, T. O'Kane, D. Monselesan, C. Franzke, and I. Horenko, 2018: On the dynamics of austral heat waves. J. Geophys. Res. Atmos., 123, 38-57, https://doi.org/10.1002/2017JD027222.

Schultz, D., W. Bracken, and L. Bosart, 1998: Planetary- and synoptic-scale signatures associated with Central American cold surges. Mon. Wea. Rev., 126, 5-27, https://doi.org/10.1175/ 1520-0493(1998)126<0005:PASSSA $>2.0$. CO;2.

Simmonds, I., and T. Richter, 2000: Synoptic comparison of cold events in winter and summer in Melbourne and Perth. Theor. Appl. Climatol., 67, 19-32, https://doi.org/10.1007/ s007040070013.

— and H. Rashid, 2001: An investigation of a dramatic cold outbreak over southeast Australia. Aust. Meteor. Mag., 50, 249-261.

Takaya, K., and H. Nakamura, 1997: A formulation of a waveactivity flux for stationary Rossby waves on a zonally varying basic flow. Geophys. Res. Lett., 24, 2985-2988, https://doi.org/ 10.1029/97GL03094.

— wave-activity flux for stationary and migratory quasigeostrophic eddies on a zonally varying basic flow. J. Atmos. Sci., 58, 608-627, https://doi.org/10.1175/1520-0469(2001)058<0608: AFOAPI $>2.0 . \mathrm{CO} ; 2$.

Tamarin-Brodsky, T., K. Hodges, B. Hoskins, and T. Shepherd, 2019: A dynamical perspective on atmospheric temperature variability and its response to climate change. J. Climate, 32, 1707-1724, https://doi.org/10.1175/JCLI-D-18-0462.1.

Teng, H., and G. Branstator, 2017: Causes of extreme ridges that induce California droughts. J. Climate, 30, 1477-1492, https:// doi.org/10.1175/JCLI-D-16-0524.1.

- — - H. Wang, G. Meehl, and W. Washington, 2013: Probability of US heat waves affected by a subseasonal planetary wave pattern. Nat. Geosci., 6, 1056-1061, https://doi.org/ 10.1038/ngeo1988.

Thompson, D., and J. Wallace, 1998: The Arctic oscillation signature in the wintertime geopotential height and temperature fields. Geophys. Res. Lett., 25, 1297-1300, https://doi.org/ 10.1029/98GL00950. 
and S. Solomon, 2002: Interpretation of recent Southern Hemisphere climate change. Science, 296, 895-899, https:// doi.org/10.1126/science.1069270.

Tozer, C., J. Risbey, T. O'Kane, D. Monselesan, and M. Pook, 2018: The relationship between wave trains in the Southern Hemisphere storm track and rainfall extremes over Tasmania. Mon. Wea. Rev., 146, 4201-4230, https://doi.org/10.1175/ MWR-D-18-0135.1.

Trewin, B., 2013: A daily homogenised temperature dataset for Australia. Int. J. Climatol., 33, 1510-1529, https://doi.org/ 10.1002/joc. 3530
Wallace, J. M., and D. S. Gutzler, 1981: Teleconnections in the geopotential height field during the Northern Hemisphere winter. Mon. Wea. Rev., 109, 784-812, https://doi.org/10.1175/ 1520-0493(1981)109<0784:TITGHF>2.0.CO;2.

Xie, Z., R. Black, and Y. Deng, 2019: Planetary and synoptic-scale dynamic control of extreme cold wave patterns over the United States. Climate Dyn., https://doi.org/10.1007/s00382-019-04683-7, in press.

Zheng, B., S. Chapman, J. Christopher, T. Frederiks, and K. Chenu, 2015: Frost trends and their estimated impact on yield in the Australian wheatbelt. J. Exp. Bot., 66, 3611-3623, https://doi.org/10.1093/jxb/erv163. 